\title{
FLEXURAL BEHAVIOUR OF STEEL PANELS COMPOSED OF BOLTED MODULAR UNITS
}

\author{
H.T. Wong ${ }^{1}$, J.G. Teng ${ }^{1, *}$, Z.C. Wang ${ }^{2}$, Y. Zhao ${ }^{3}$ and S.L. Dong ${ }^{3}$ \\ ${ }^{1}$ Department of Civil and Structural Engineering \\ The Hong Kong Polytechnic University, Hong Kong, China \\ ${ }^{2}$ Research Centre for Spatial Structures, Shanghai Jiaotong University, Shanghai, China \\ ${ }^{3}$ Department of Civil Engineering, Zhejiang University, Hangzhou, China \\ *Corresponding author. Email: cejgteng@polyu.edu.hk; Fax: +852 2334 6389; Tel: +852 27666012
}

\begin{abstract}
Steel-concrete composite shell roofs (Comshell roofs) are formed by pouring concrete on a thin stiffened steel base shell which serves as both the permanent formwork and the tensile steel reinforcement. The thin steel base shell, constructed by bolting together open-topped modular units consisting of a base plate and surrounding edge plates, are required to carry the wet concrete loading safely during construction. The behaviour of these bolted shells is complicated by the presence of many bolted joints, so the use of finite element analysis is necessary in order to accurately predict their behaviour. For any such finite element model, the key issue is the accurate modelling of the behaviour of the bolted connections within a bolted steel base shell in which bending and membrane actions exist in both directions. In this paper, bolted flat panel specimens under transverse loading are studied to develop a good understanding of the behaviour of such bolted connections and to assess the validity of a relatively simple finite element connection model developed in a previous study. Experimental results obtained from a series of flexural tests on model bolted panels are presented together with those from finite element analyses in which the existing simplified connection model was employed. Comparisons of results from these two approaches confirm that the simplified connection model proposed in a previous study leads to accurate predictions of the flexural behaviour of these present bolted panels.
\end{abstract}

Keywords: Shell roofs, bolted steel panels, buckling, bolted connections, finite element analysis, bolted steel shells

\section{INTRODUCTION}

Many thin concrete shells have been built around the world as large span roofs, but their use has gradually declined over the past few decades. This decline has been due mainly to the high cost of construction and removal of temporary formwork and associated falsework for concrete casting in the construction of a thin concrete shell. This labour intensive and costly process of construction, coupled with the increasing ease in analysing complex skeletal spatial structures offered by advances in computer technology, has made concrete shells much less competitive than they were a few decades ago.

Over the past few decades, there have been several attempts aimed at eliminating the need for temporary formwork in constructing thin concrete shell roofs, but these have met with only limited success. An excellent review of these attempts and other developments of thin concrete shell roofs was given by Medwadowski [1], who concluded that forming "remains the great, unsolved problem of construction of concrete thin shell roofs. Any and all ideas should be explored, without prejudice.” The latest development in the forming of thin concrete shell roofs is the Comshell roof system proposed by Teng [2] which is believed to be a very promising solution to this difficult problem (Teng et al. [3]).

The Comshell roof is a steel-concrete composite shell roof formed by pouring concrete on a thin stiffened steel base shell which serves as both the permanent formwork and the tensile steel 
reinforcement. The steel base shell is constructed by bolting together modular steel units in the form of an open-topped box consisting of a flat or slightly curved base plate surrounded by edge plates (Figure 1). By adopting modular units of different shapes, different shell forms can be achieved, but current research is limited to cylindrical shell roofs only (Figure 2) as they are the easiest to construct by this modular approach (Teng et al. [3]). A brief description of the system and its advantages is given here, but further details are available elsewhere (Teng [2]; Teng et al. [3]).

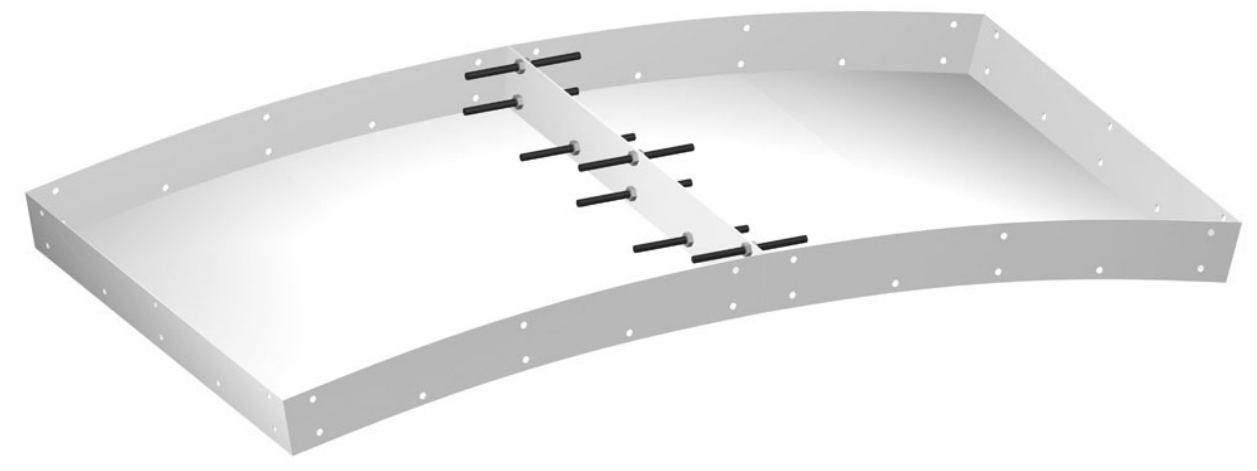

Figure 1. Modular units and bolted connection

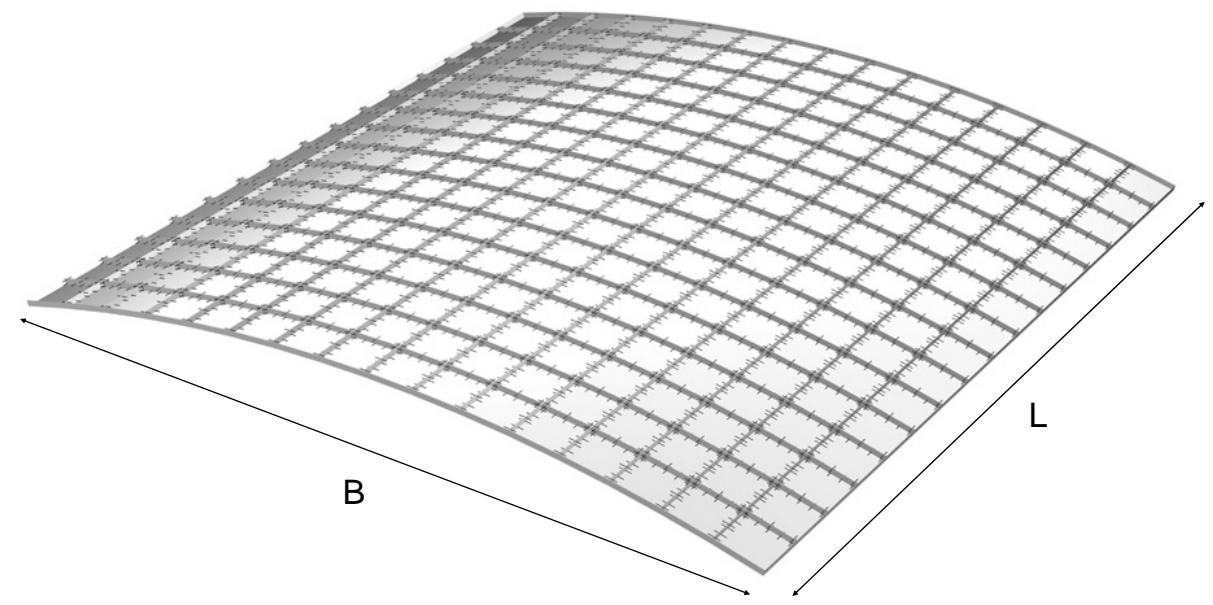

Figure 2. Steel base shell formed from modular units

The modular units for cylindrical shell roofs are made with two of the edge plates slightly inclined, so that when they are assembled using bolts, a curved profile of desired curvature results (Figures 1 and 2). Holes are drilled on the edge plates for bolt connections to adjacent units, and the bolted-together edge plates form stiffeners in both directions (Figure 2). The circular profile of the shell can be either approximated by flat bases, or exactly followed by slightly curved bases with all edge plates being perpendicular to the base. In fact, the base of modular units can have curvatures which differ from the global curvature of the roof, and can be either convex or concave, if desired.

This system has many distinct advantages: (a) mass factory production of the units of a few standard sizes and curvatures is possible, so shells of desired spans and curvatures can be built easily; (b) transportation to and handling on site is easy, and units can be bolted together to form big panels on the ground (e.g. half-span arch panels) for lifting; (c) the steel shell so built has many rib stiffeners formed from edge plates, and as a result, its buckling resistance is substantially enhanced so shoring during construction can be substantially reduced; (d) the ribs can prevent wet concrete 
from flowing down the shell surface; (e) the ribs together with bolts act as shear connectors between the steel shell and the concrete, so additional welded shear connectors are not required; and (f) the ribs can be used as spacers to ensure accurate positioning of steel reinforcing bars/wire meshes for controlling cracks or for hogging moment resistance. It may be noted that the edge plates of the modular units fulfil many useful roles.

Steel sheets with a thickness of around $2 \mathrm{~mm}$ are expected to be sufficient for the base plate of the modular unit to carry wet concrete loading without excessive deformations, stresses or premature local buckling, particularly if small corrugations are used in the base to enhance its out-of-plane stiffness (Teng et al. [3]). Due to this small thickness, the units can be press-formed easily with precise geometric control. The units can be assembled into arch panels on ground before lifting, ensuring a tight control of the geometric shape of the assembled shell and limiting shoring requirement.

For the Comshell system to be widely used in practice, many issues have to be studied to establish a sound understanding of the behaviour and strength of these shells, and to develop suitable design methods. At the present, a number of failure modes have been identified (Teng et al. [3]), and each needs a great amount of research. A main design issue of Comshell roofs is the buckling strength of the bolted steel base shell during the construction stage under wet concrete loading. Due to the many bolted connections, the behaviour of these bolted base shells is complicated, so the use of finite element analysis is necessary at the present in order to accurately predict their behaviour, although a simpler method may be established in the more distant future. For any such finite element model, the key issue is the accurate modelling of the behaviour of the bolted connections within a bolted steel base shell, in which bending and membrane actions exist in both directions.

The aim of the present study was to develop a good understanding of the behaviour of the bolted connections in Comshell roofs under one-way or two-way bending and to assess the validity of a relatively simple finite element connection model developed in a previous study (Teng et al. [3]). Experimental results obtained from a series of flexural tests on model bolted flat panels are presented together with those from finite element analyses in which the existing simplified connection model was employed. The use of bolted flat panels simplified the experimental work and allowed attention to be focused on the flexural behaviour of the connections. This then forms a solid basis for further research into the behaviour and modelling of these bolted connections in a curved bolted steel base shell of the Comshell roof.

\section{GENERAL EXPERIMENTAL CONSIDERATIONS}

During the construction stage, the wet concrete acts as loading on the bolted steel base shell which can fail by either local buckling or overall buckling (Teng et al. [3]). Local buckling can be in one of two modes: buckling of the bolted stiffeners formed from edge plates with or without stiffening lips, and buckling of the base plates of the modular units. Overall buckling of the bolted base shell involves global shape changes, while local buckling only involves deformations of either the stiffeners or the base plates or both.

With the availability of powerful computer software for nonlinear analysis of shells, the purpose of experiments is mainly to calibrate numerical models instead of providing a parametric behavioural 
study. Such calibration is essential when there are theoretical uncertainties in numerical modelling. Typical uncertainties in modelling the nonlinear and buckling behaviour of steel structures include geometric imperfections, residual stresses and connection behaviour. All these aspects are present in the bolted base shell of a Comshell roof, but the uncertainty of the connection behaviour is the predominant aspect. Therefore, the accurate modelling of the behaviour of the bolted connections is the key to the accurate prediction of the buckling load of bolted steel base shells.

As a first step towards understanding the behaviour and modelling of these bolted connections, simple cantilever connection tests were previously conducted, and experimental results together with results from numerical simulations are given in Teng et al. [3]. This study led to the development of a relatively simple connection model in addition to a refined model. The simpler model, referred to as the simplified connection model, was shown to be efficient and sufficiently accurate, and thus has the potential to be used in the nonlinear analysis of bolted steel base shells of the Comshell roof system. The connections investigated in the study of Teng et al. [3] were not "complete" connections, in the sense that the edge plate of a modular unit was bolted to a rigid support plate, but in real bolted steel base shells, a connection is formed by connecting two deformable edge plates of adjacent modular units by bolts. An obvious difference between these two types of connections is that buckling of the bolted edge plate cannot occur in the former type of connection. While the cantilever tests provided useful test data for understanding the connection behaviour and for the development of a simplified finite element connection model, the natural next step of this research would be to examine the behaviour and modelling of more realistic bolted connections. This paper therefore presents such a study in which the flexural behaviour of bolted stiffened panels were tested and modelled, with particular attention to connection behaviour and buckling phenomena.

\section{FABRICATION OF SPECIMENS}

This series of tests, referred to as the BP series, consisted of four tests on three bolted panel specimens. The three panel specimens were of two configurations and subjected to different loadings. The three panels are referred to as specimens BP1, BP2 and BP3. Two tests were conducted on specimen BP3, which are referred to as test BP3-1 and test BP3-2.

The three panel specimens were constructed from two types of modular units. Specimen BP1 was formed by bolting together two modular units, each of which had a $300 \mathrm{~mm}$ x $300 \mathrm{~mm}$ base plate and four $30 \mathrm{~mm}$ high edge plates each stiffened with a $10 \mathrm{~mm}$ wide lip (Figure 3a). This height of the edge plates meant that only one row of bolts with washers could be accommodated. Specimens BSP2 and BSP3 were constructed by bolting together nine modular units into a square panel, with the central unit being surrounded by other modular units on all four sides and representing closely a modular unit in a much larger panel in terms of interaction with adjacent modular units. The modular units for specimens BSP2 and BSP3 had a $500 \mathrm{~mm}$ x $500 \mathrm{~mm}$ base plate and four $60 \mathrm{~mm}$ high edge plates (Figure $3 b$ ). The greater height of the edge plates of these two specimens allowed the use of two rows of bolts with washers at connections. All four edge plates were perpendicular to the flat base in these modular units. The choices of dimensions were made, taking into account the requirements of the corresponding model base shell tests (Wong and Teng [4]). 


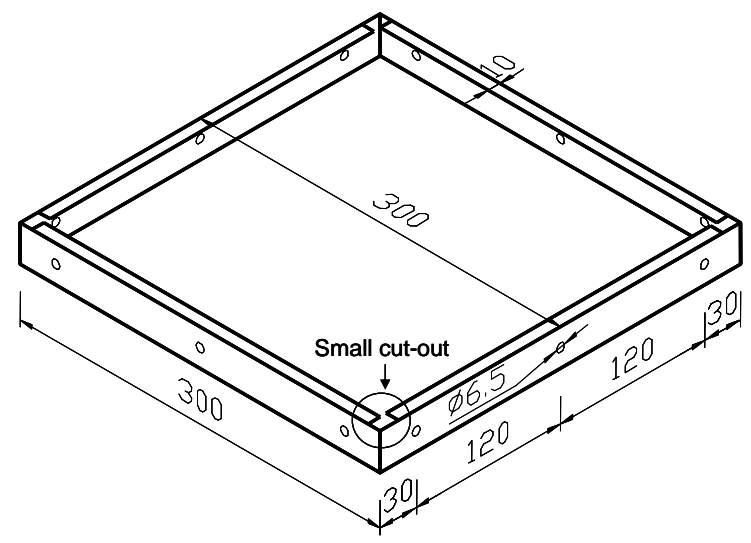

(a) Unit for specimen BP1

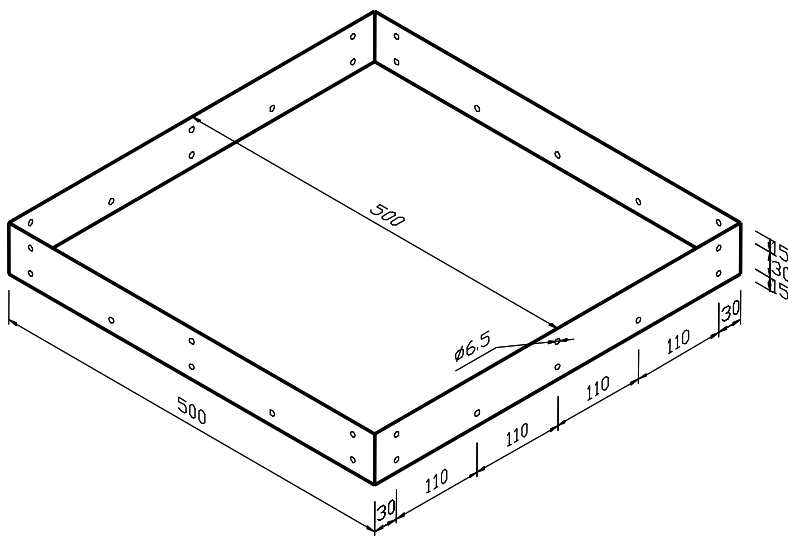

(b) Unit for specimen BP2 and BP3

Figure 3. Dimensions of modular units

Zinc-galvanized cold-formed steel sheets with a nominal thickness of $1 \mathrm{~mm}$ were used to fabricate the modular units. This thickness was chosen because sheets of this thickness are commonly available and are suitable for the necessary welding involved in the fabrication process. Material properties of the steel sheets were determined by tensile tests according to BSEN1002-1 [5]. Table 1 provides the material properties of the steel sheets averaged from the results of three tensile tests, where the percentage elongation after fracture is for a $50 \mathrm{~mm}$ gauge length. Selected stress-strain curves of the steel sheets used in the fabrication of these specimens are shown in Figure 4. The tensile stress-strain curves from other tests not shown herein are very similar to these selected curves. These tensile test results were used to define the material behaviour in the subsequent finite element analyses. The material properties were calculated using the sheeting thicknesses that included coatings, which partly explains why the elastic moduli of the steel sheets found from the tensile tests are on the lower side of values for steels.

Table 1. Material properties of steel sheets

\begin{tabular}{c|c|c|c|c|c}
\hline Panel specimen & $\begin{array}{c}\text { Thickness } \\
\mathbf{t}(\mathbf{m m})\end{array}$ & $\begin{array}{c}\text { Young's } \\
\text { modulus } \\
E \mathbf{( G P a )}\end{array}$ & $\begin{array}{c}\text { Yield stress } \\
\sigma_{y} \mathbf{( M P a )}\end{array}$ & $\begin{array}{c}\text { Tensile strength } \\
\sigma_{u}(\mathbf{M P a})\end{array}$ & $\begin{array}{c}\text { Ultimate Elongation } \\
\boldsymbol{\varepsilon}_{u}(\mathbf{\%})\end{array}$ \\
\hline BP1 & 1.03 & 183.68 & 282 & 344 & 29.6 \\
\hline BP2 and BP3 & 1.03 & 189.01 & 278 & 323 & 26.3 \\
\hline
\end{tabular}

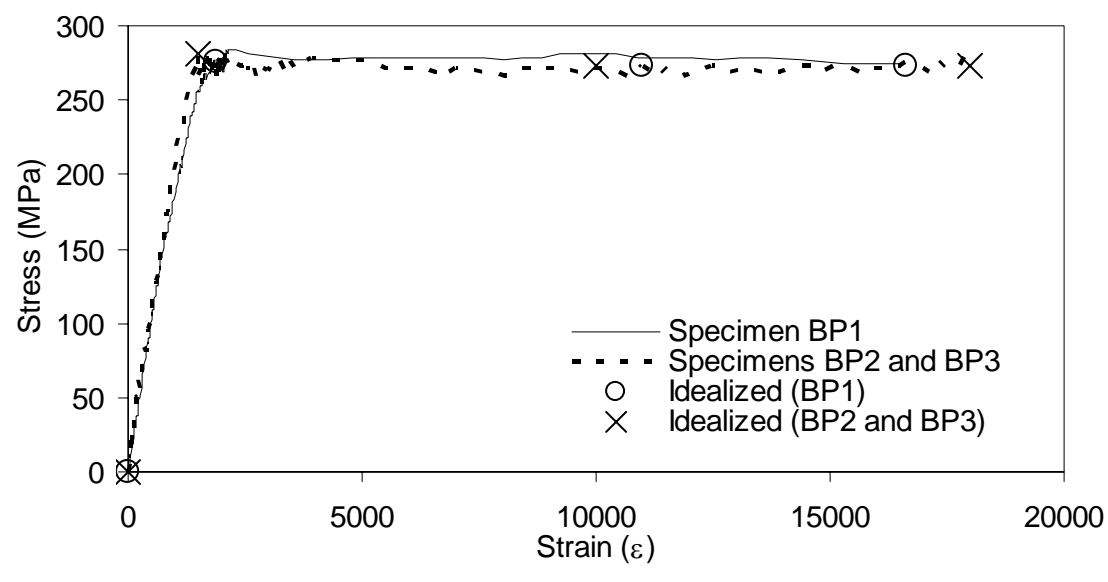

Figure 4. Typical stress-strain curves of steel sheets from tensile tests 
While stamping is expected to be the forming process for the modular units in future practical applications, and can be easily realized by a commercial manufacturer if a large number of units are required, the fabrication of the experimental modular units had to follow a simpler approach. The fabrication of these experimental modular units involved the steps of cutting, drilling, bending and welding. First, a square steel sheet with four corner cut-outs and pre-drilled holes were obtained. Second, a numerically controlled bending machine was employed to fold the four edge plates to form a $90^{\circ}$ angle. Third, the four corners were welded to obtain a modular unit in the form of an open-topped box (Figure 3). To achieve high quality welding, a TRANSTIG 16Pi pulsed TIG (Tungsten Inert Gas) welding machine was employed. Finally, the excess welding deposits were ground away to provide smooth and clean edges. Despite much care exercised in the fabrication process, it was noticed that the modular units so produced had slightly convex or concave base plates. In addition, in fabricating specimens BP2 and BP3, the bolt holes, which were manually drilled, were not as accurately positioned as initially expected, which led to slight unevenness between the modular units after their assembly into a panel. Modifications to the fabrication process to avoid this problem were subsequently implemented in a follow-on series of tests on bolted steel shells (Wong and Teng [4]).

\section{EXPERIMENTAL SET-UP}

\subsection{Test BP1}

A simply supported one-way panel test was first conducted on specimen BP1 (Figure 5) to study the behaviour of a bolted steel panel. Loading was applied by weights hung at the mid-span corners of the modular unit at an increment of $10 \mathrm{~N}$ per loading point (Figure 5). Three linear variable differential transformers (LVDTs) were placed at the mid-span for the measurement of vertical displacements. Strain gauges were not installed, as the test was intended to provide a preliminary assessment of connection behaviour in a panel.

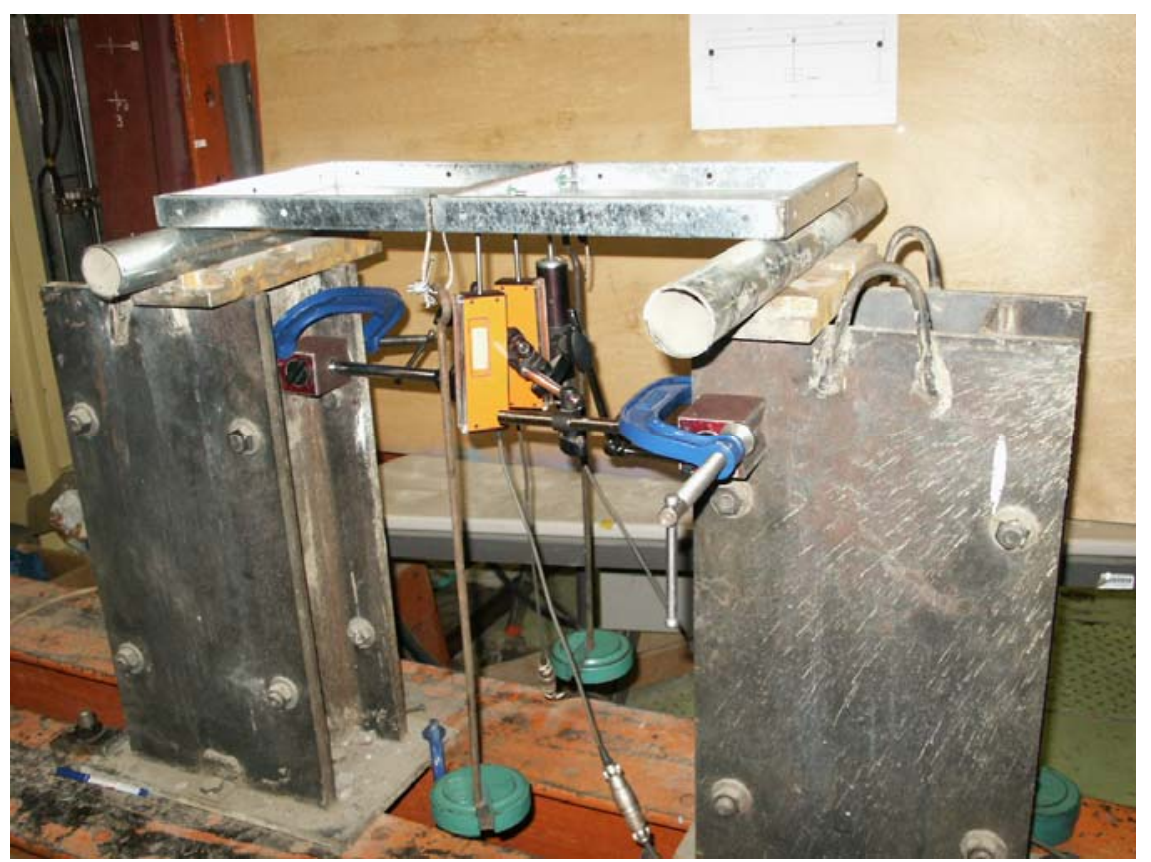

Figure 5. Experimental set-up for specimen BP1 
The experimental set-up for test BP2 is shown in Figure 6, where three components can be identified: the loading boxes, the supporting system and the bolted steel panel specimen. The square panel specimen rested on roller supports on all four sides. It is well-known that square plates so supported will experience uplifting movements in the corner regions (Timoshenko and Woinowsky-Kreieger [6]), so the edges were not strictly simply-supported. These supports were used as they could be easily achieved and could also be dealt with in the numerical modelling work.

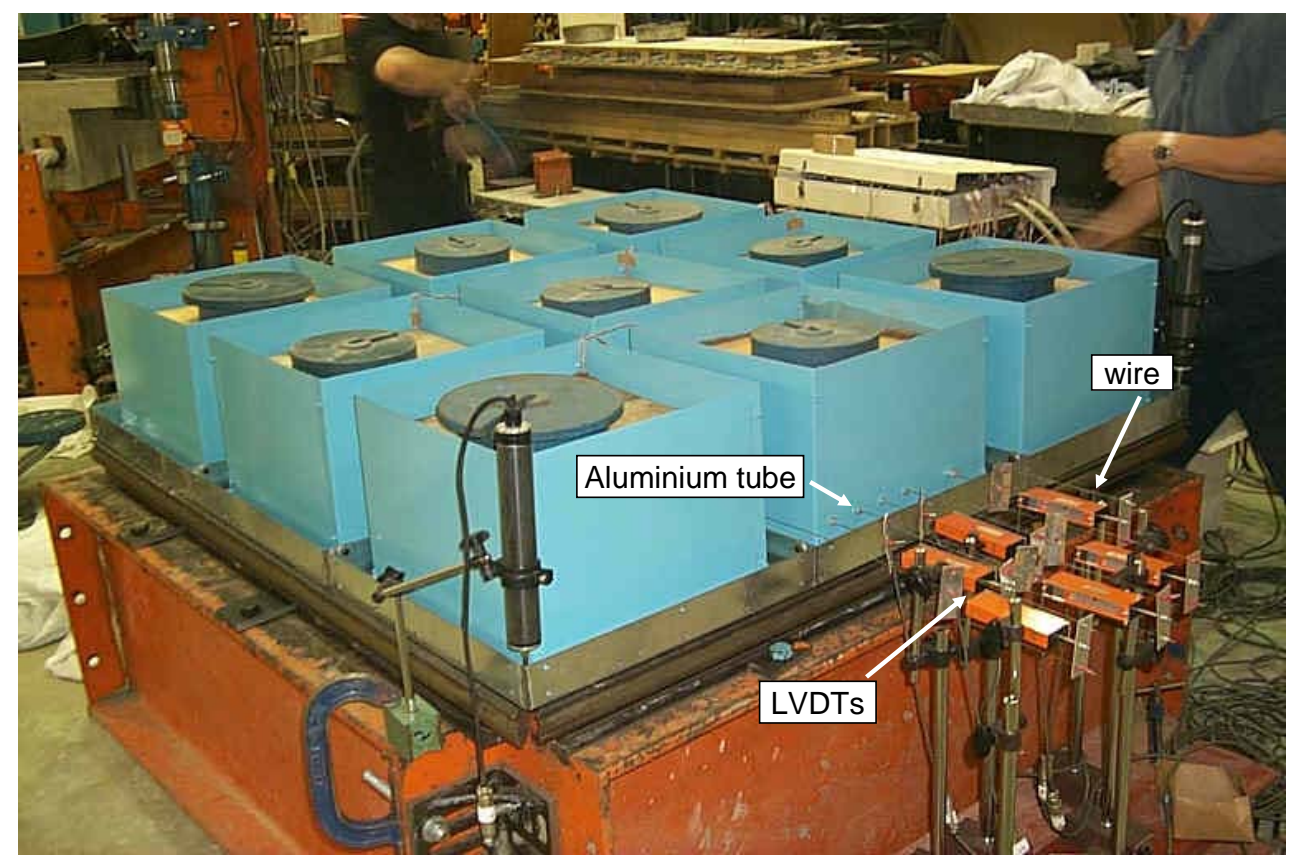

Figure 6. Experimental set up for BP2

The loading boxes were filled with sand, on the top of which dead weights were added, to simulate a uniformly distributed load corresponding to wet concrete loading during construction. In test BP2, a loading box with a plan size of $400 \mathrm{~mm} \times 400 \mathrm{~mm}$ and a height of $300 \mathrm{~mm}$ was placed in each modular unit (Figure 6), so the loading box was a little smaller than the base plate to avoid possible contact between the edge plates and the loading box. The smaller boxes also allowed the deformations of the stiffeners to be observed and measured during the test.

Two tests were conducted on specimen BP3: test BP3-1 and test BP3-2. An overall view of the set-up for test BP3-1 is shown in Figure 7. In this test, loading was applied to the central unit only through a single loading box with a plan size of $500 \mathrm{~mm} \times 500 \mathrm{~mm}$ and a height of $400 \mathrm{~mm}$, and vertical supports were provided at the four corners of the central unit (Figure 8). This test was to approximately simulate the unfavourable condition of a single modular unit being loaded while all adjacent units are still empty. In a curved shell, the edges of the loaded unit are unlikely to experience significant translational displacements due to the presence of curvature, which explains the provision of vertical supports to the central unit in test BP3-1. This test also provided a relatively simple check of the numerical model. 


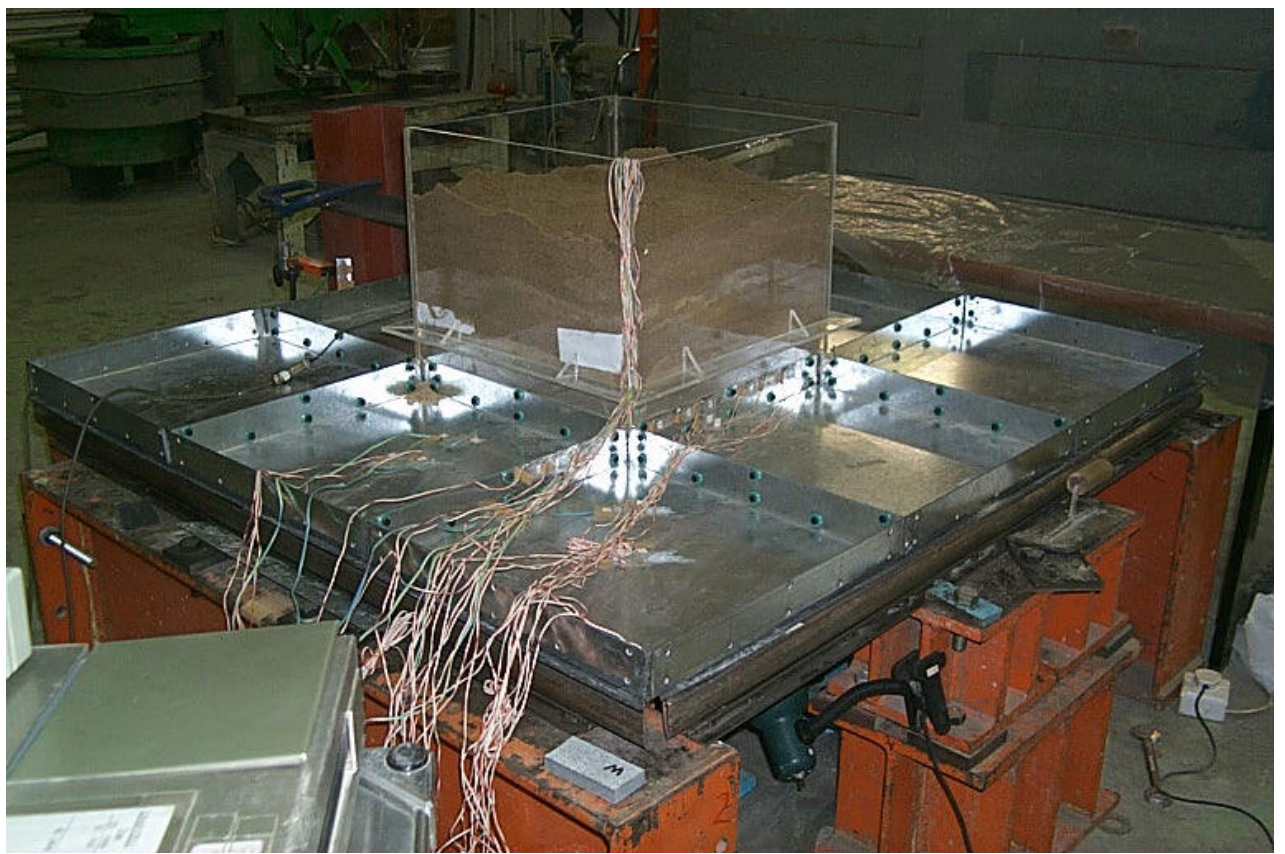

Figure 7. Experimental set-up for test BP3-1

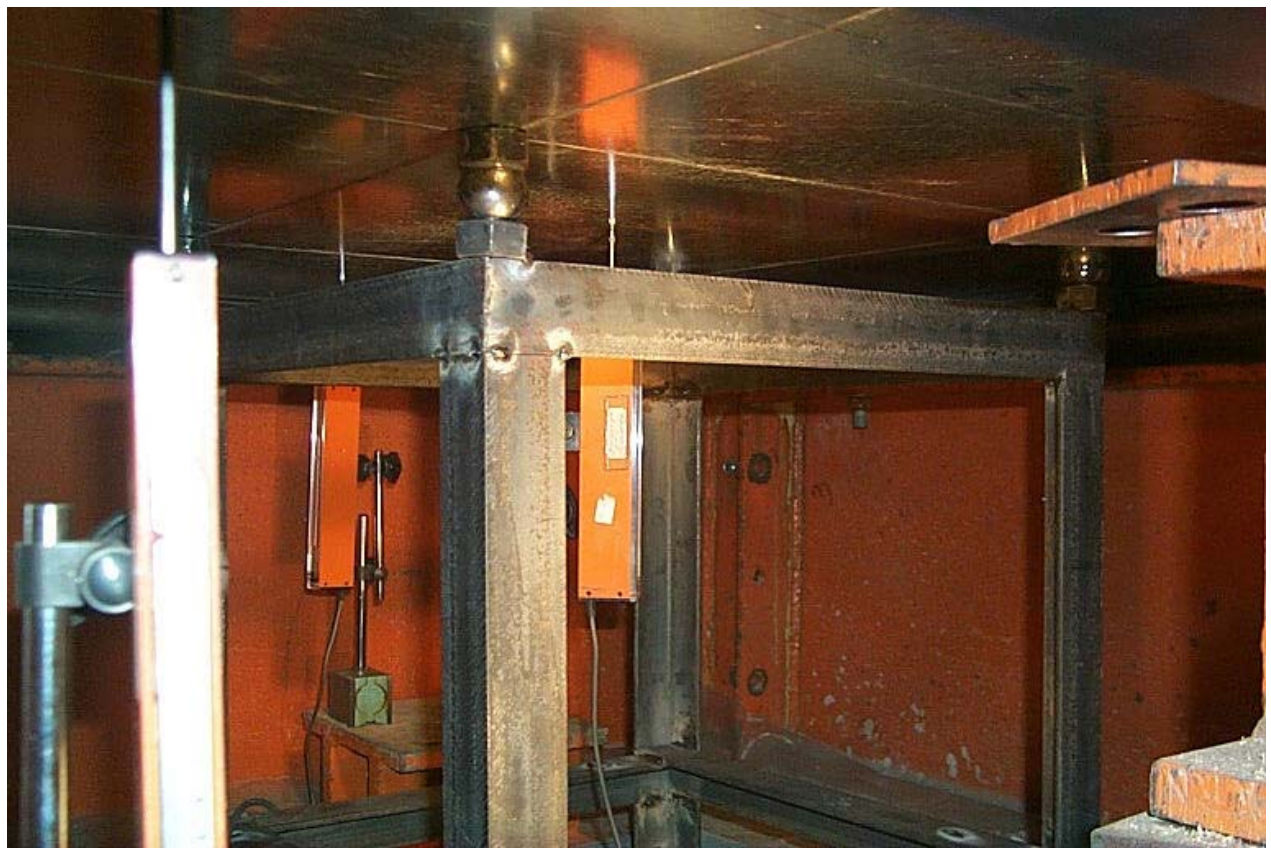

Figure 8. Support frame for the central unit in test BP3-1

The set-up for test BP3-2 is similar to that for test BP2 shown in Figure 6. The only difference is that a uniform layer of sand was applied to the entire specimen. The sand was contained by a single loading box with a plan size of $1500 \mathrm{~mm} \times 1500 \mathrm{~mm}$ and a height of $300 \mathrm{~mm}$. If the loading on specimen BP2 can be approximated as being uniformly distributed over the entire panel and that the sand did not provide a significant restraint to the deformation of the bolted stiffeners, the difference between tests BP2 and BP3-2 is expected to be small. As tests BP3-1 and BP3-2 were conducted on the same panel, in test BP3-1, yielding of steel and excessive deformations were avoided. 
The supporting frame was fabricated mainly using $533 \mathrm{~mm} \times 210 \mathrm{~mm}$ x $20 \mathrm{~mm}$ universal I-section beams (Figure 9). Along each of the four edges, the test panel rested on a bearing plate welded to a steel tube ( $\mathrm{D}=60 \mathrm{~mm}$ ) directly. This support arrangement allowed the up-lifting of the panel at the corners. Lubricating oil was applied to both surfaces of the steel angle and the bearing tube to minimize any friction to allow the steel tube to rotate freely. As some slight unevenness between the modular units existed in the panel, the specimen and the support bearing plate were not in complete contact over some small parts of the edges. These small gaps tended to close up as the applied loading increased.

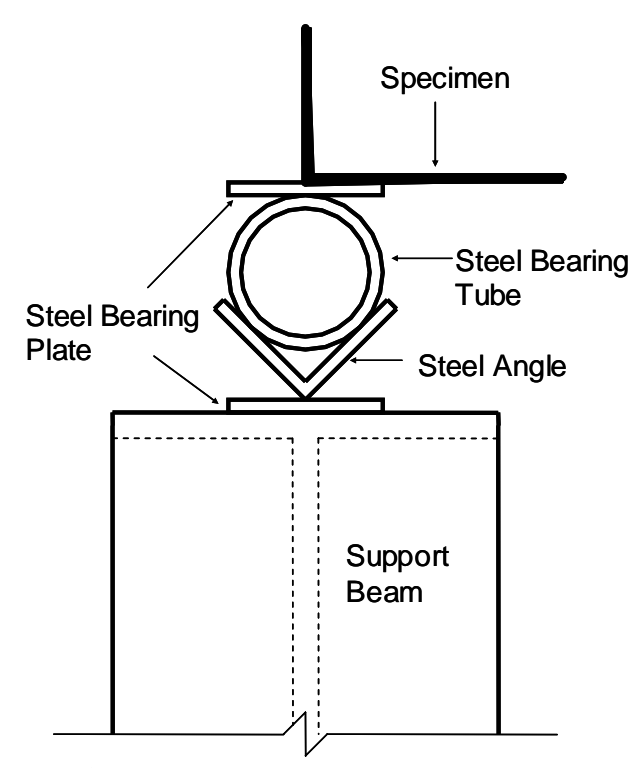

Figure 9. Cross-section of the support

A number of LVDTs were used to measure the vertical displacements in all three tests, with most of them being placed under the base plates. Although it was desirable to measure the deformed shapes of the stiffeners of specimen BP2, which were available for observations, there was not enough space to install LVDTs or dial gauges. As a result, an indirect method was adopted for the measurement of stiffener deformations in the present study. In this method, a set of wires with aluminium tube covers were led through one of the loading boxes located near the edge (Figure 6). Each wire was connected to the top edge of the selected stiffener (stiffener II in Figure 10b) at one end and to an LVDT at the other end, and the LVDTs were placed on the ground nearby the panel (Figure 6). The aluminium tubes, which kept the sand sway from the wires, were fixed onto the loading box and the wire and the tube did not come into contact during the loading process. With this method, the six LVDTs placed nearby the specimen provided measurements of the out-of-plane deformations of stiffener II. The positions measured by these six LVDTs are shown in Figure 10. No stiffener deformations were measured in test BP3-1 as local buckling was unlikely to occur and in test BP3-2, the stiffeners were buried under the sand.

Strain gauges were installed on each panel specimen to measure strain distributions on both the stiffeners and the base plates. Figures 10 and 11 show the layouts of the main strain gauges on specimens BP2 and BP3 respectively; readings from strain gauges of lesser are not discussed here. The strain gauges are simply numbered but indicated with a starting letter " $\mathrm{S}$ " when referred to in the text. Most of the strain gauges installed on the base plates were two-element and three-element rosettes, with some of them being placed at the same locations on both sides of the steel sheet. As shown in Figures 10 and 11, the main strain gauges were placed on a one-eighth portion of the specimen. The arrangements of strain gauges on the two specimens were slightly different. In specimen BP2, most of the strain gauges were placed on the soffit of the panel and those on the upper surfaces of the base plates are represented by the '*' symbol (Figure 10). In specimen BP3, all strain gauges were placed on the upper surfaces of the base plates. 


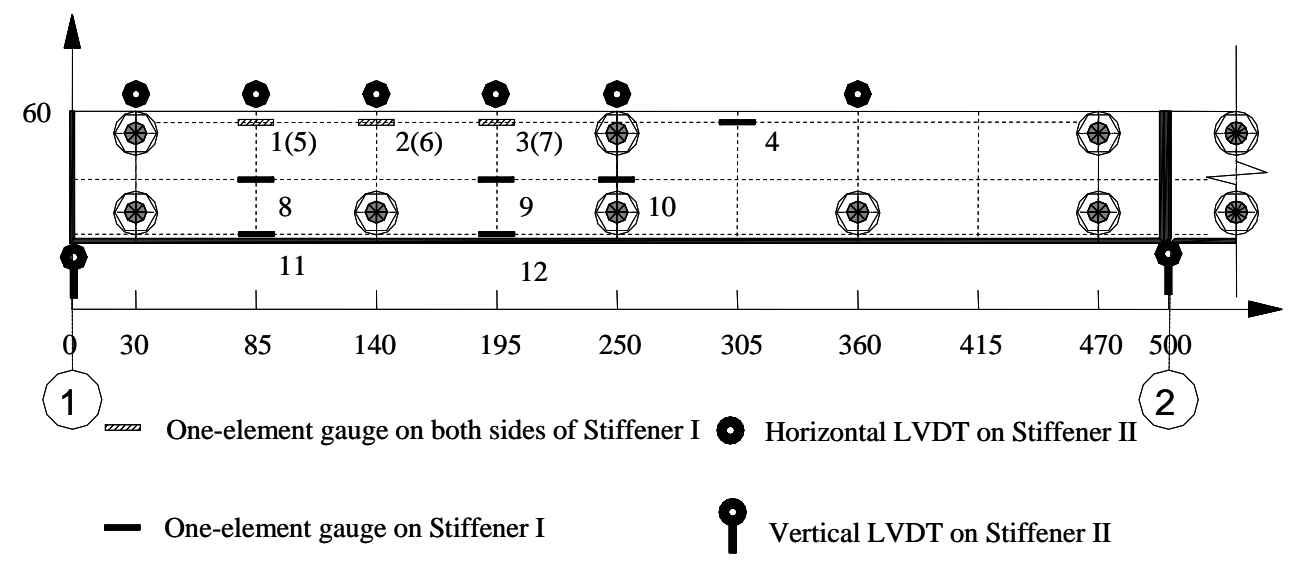

(a) Strain gauges and LVDTs on Stiffeners I and II (Section A-A)

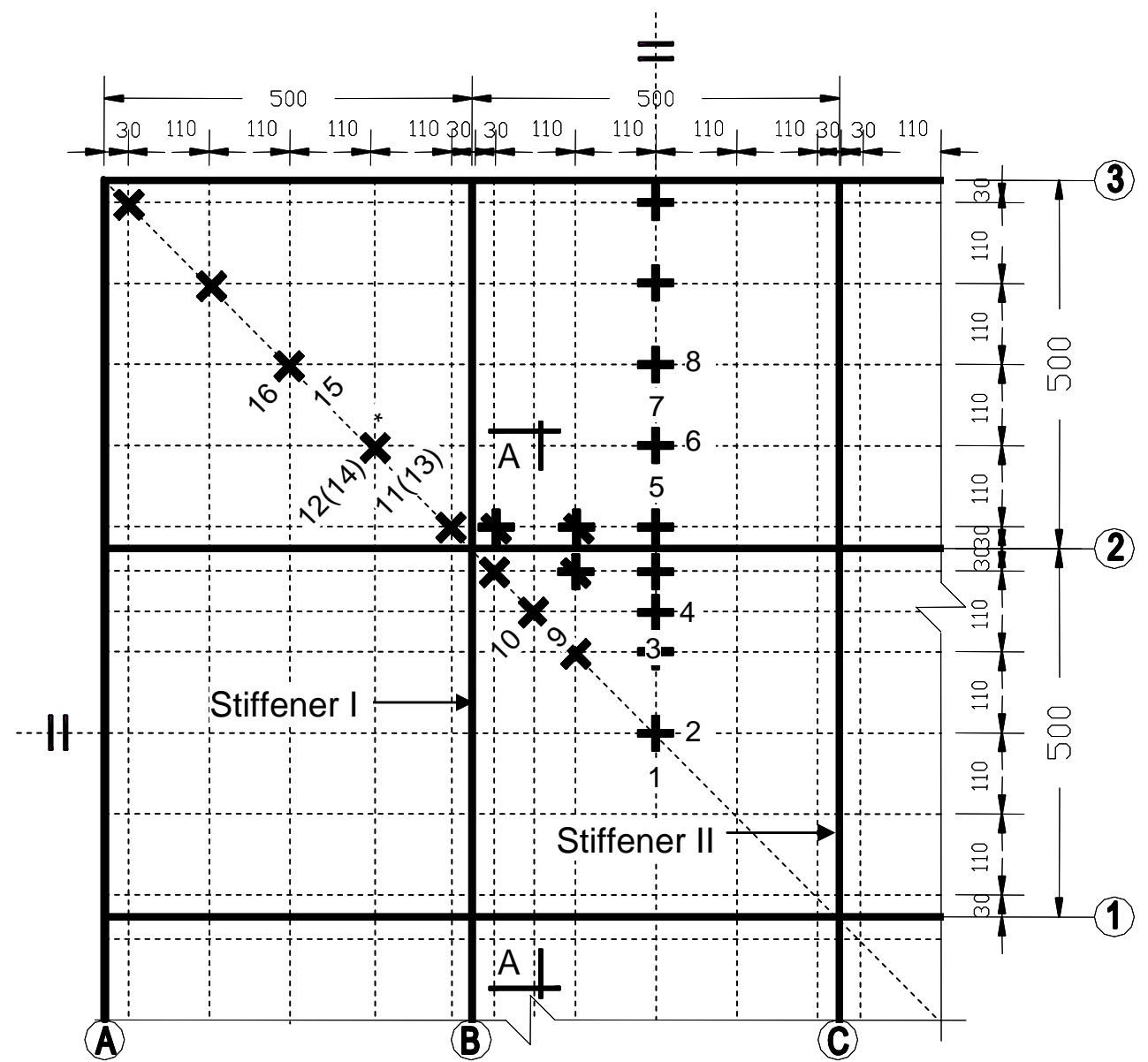

(b) Strain gauges on the base plates

Figure 10. Layouts of strain gauges and LVDTs on specimen BP2 


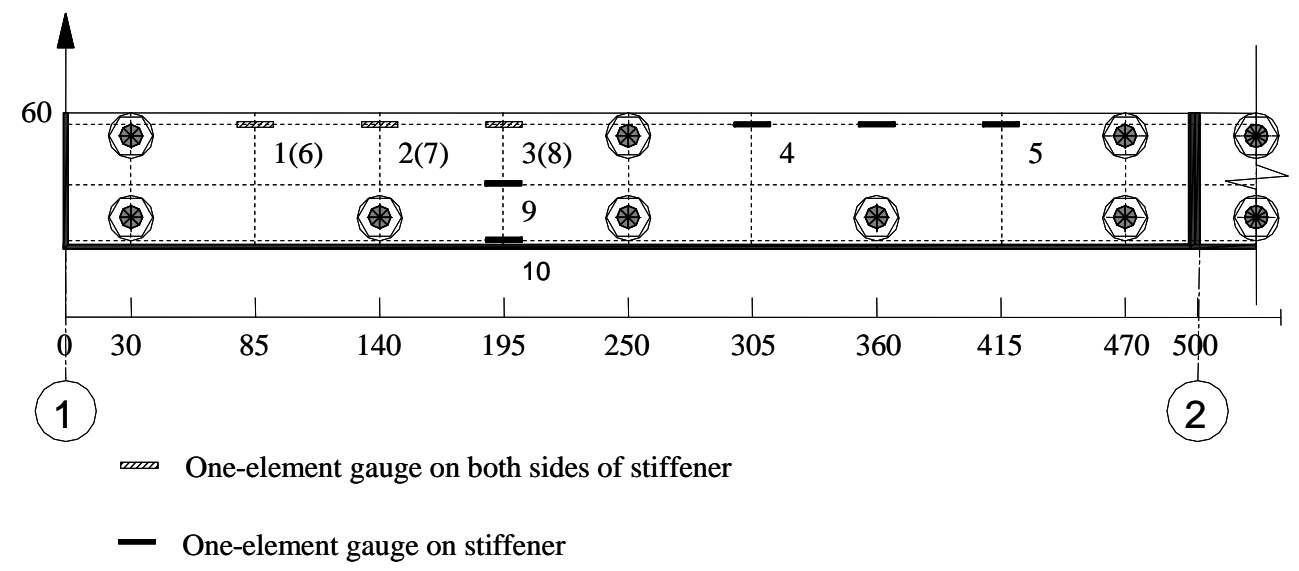

(a) Strain gauges on the selected stiffener (Section B-B)

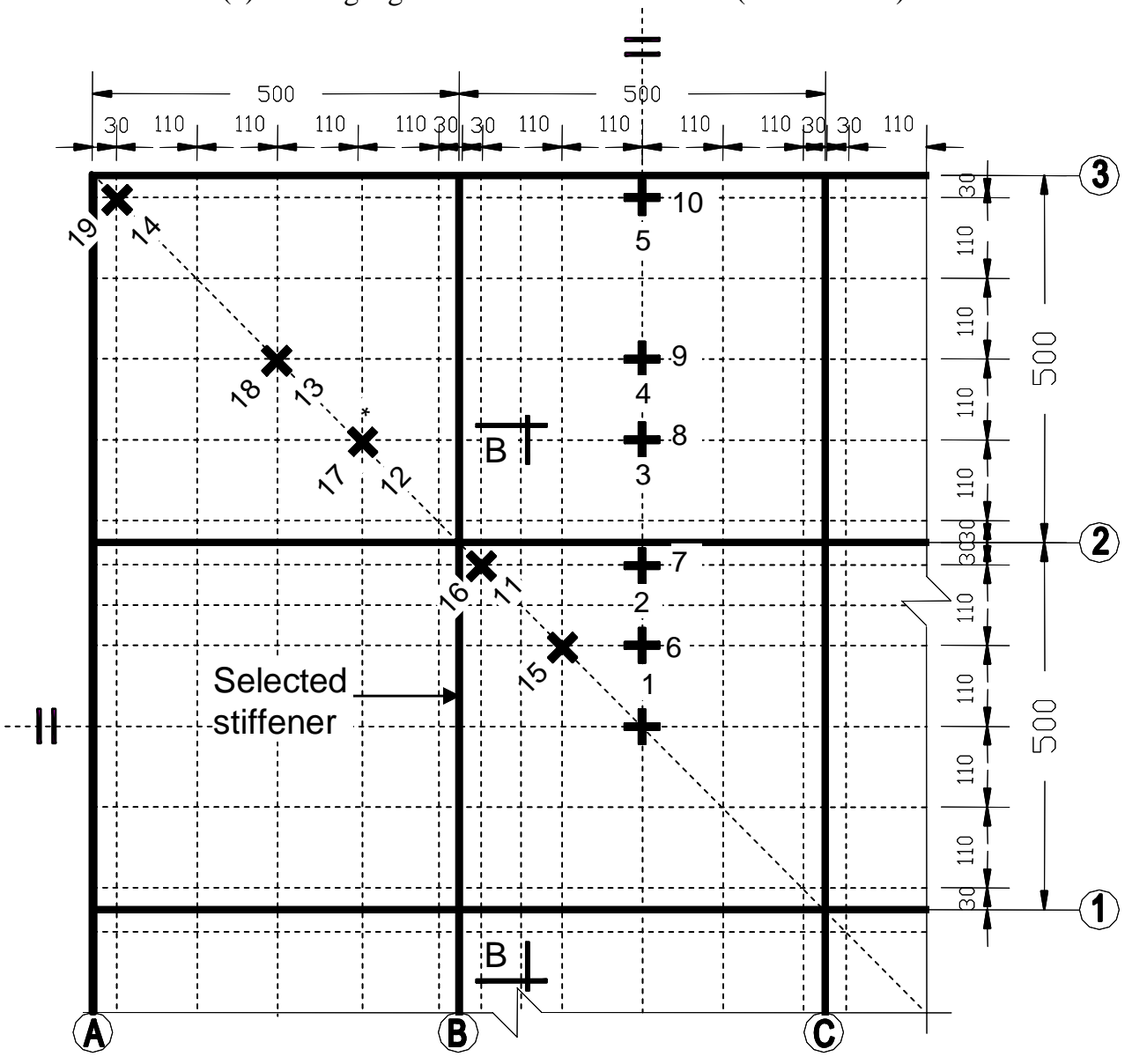

(b) Strain gauges on the base plates

Figure 11. Layouts of strain gauges on specimen BP3 


\section{EXPERIMENTAL RESULTS}

\subsection{Specimen BP1}

This was a simple experiment. The specimen was loaded until its sudden collapse. Almost throughout the entire loading process of this test, lateral deformations could not be observed on the edge plates by naked eyes. These edge plates were each stiffened with a lip, while those in specimens BP2 and BP3 were not. As a result of the stiffening lips, the edge plates in specimen BP1 had a relatively high local buckling resistance. When the applied load reached about $250 \mathrm{~N}$ per loading point, short-wave buckles were noticeable on the edge plates by naked eyes at the mid-span, where the lip stiffeners did not exist. Final collapse soon followed at a load of $270 \mathrm{~N}$ per loading point. Specimen BP1 after failure is shown in Figure 12, while the load-displacement curve of the panel centre (i.e. mid-width of the mid-span) is shown in Figure 13. No strain readings were taken during this simple test.

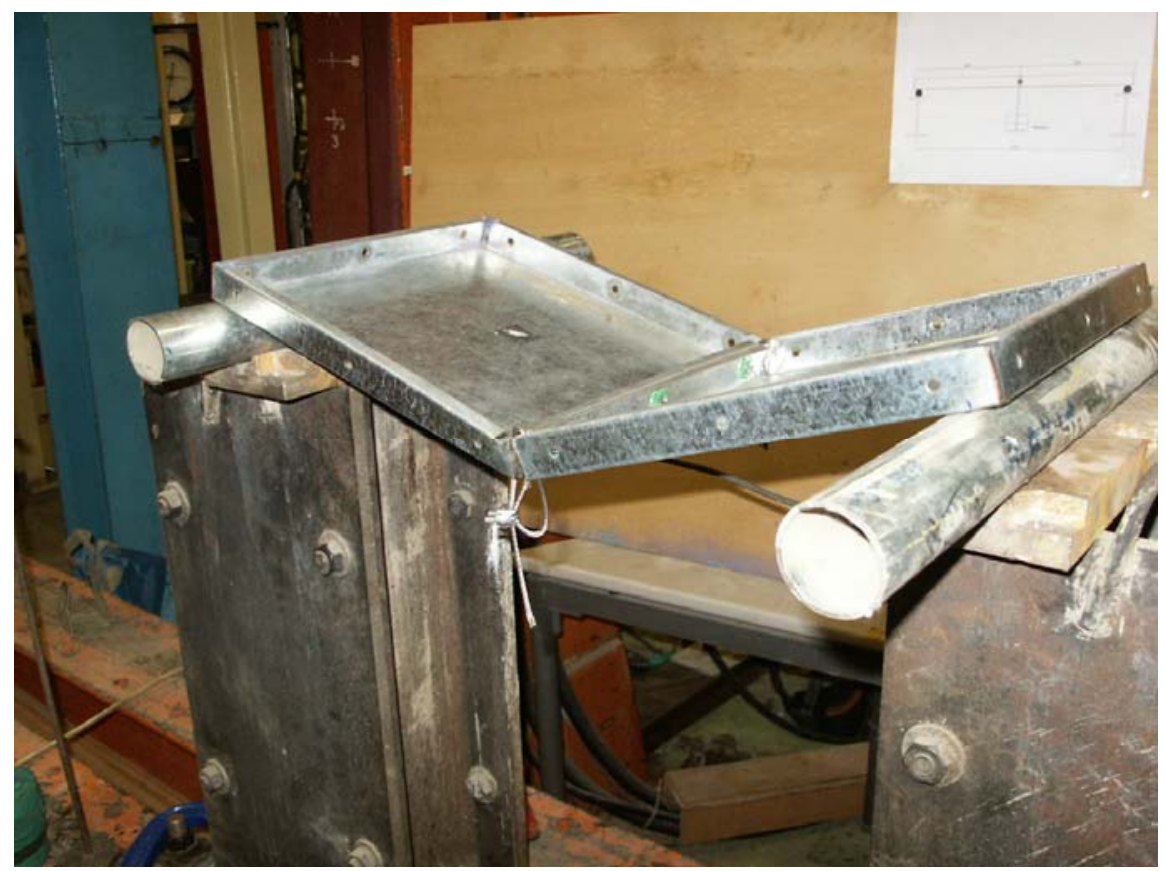

Figure 12. Failure mode of specimen BP1

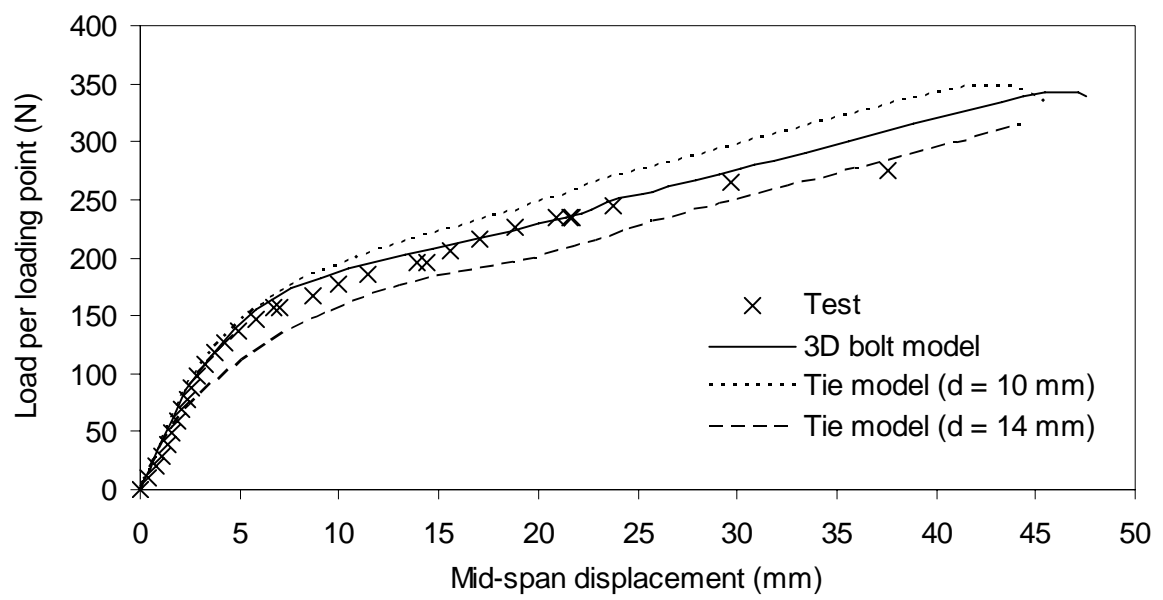

Figure 13. Load-displacement curves of specimen BP1 


\subsection{Specimen BP2}

According to the chosen loading scheme, sand was pre-packed and then filled into the loading boxes. To avoid excessive sand filling and emptying work and to limit the height of the loading boxes, standard steel weights were added to the top of the sand to apply additional loading. It was expected that through the sand layer, the steel weights produced a pressure on the modular unit which was close to being uniform, although this could not be checked. It may be noted that a higher box does not automatically mean a more uniform transfer of the steel weights to the base plate of the modular unit as a distributed pressure, as a higher box is also more like to lead to arching actions in the sand.

At a pressure of about $1.5 \mathrm{kPa}$ on the base areas of the boxes, small lateral deformations could be observed on the stiffeners around the central unit by naked eyes. These deformations continued to grow with further loading and propagated to other stiffeners outside the central unit, leading to obvious short-wave buckles of roughly similar wavelengths. These buckles grew with load increases. Some of the initial load increments proved to be too large as each step caused a large increase in deformation. The load increments were later reduced.

Figure 14 shows the variations of strains measured on stiffener I versus the total applied pressure (including those from the surcharge load and the self-weight of the filled sand). The solid lines represent the readings from those strain gauges installed close to the top edge, while the dashed and the dashed-dotted lines represent the readings from the strain gauges located at the mid-height and near the bottom edge of the stiffener, respectively. The local buckling of stiffener I is reflected by these readings, particularly those from the strain gauges near the top-edge (Figure 14). Most of the strain readings increase almost linearly with the applied load until the load reaches around $2.7 \mathrm{kPa}$. Above this load level, rapid increases are then seen in some of the strain readings, while other readings show a trend reversal. This is the load level corresponding to the local buckling of the stiffeners. Moreover, it is clear that the strains recorded near the top-edge are significantly higher than those at the mid-height and near the bottom edge.

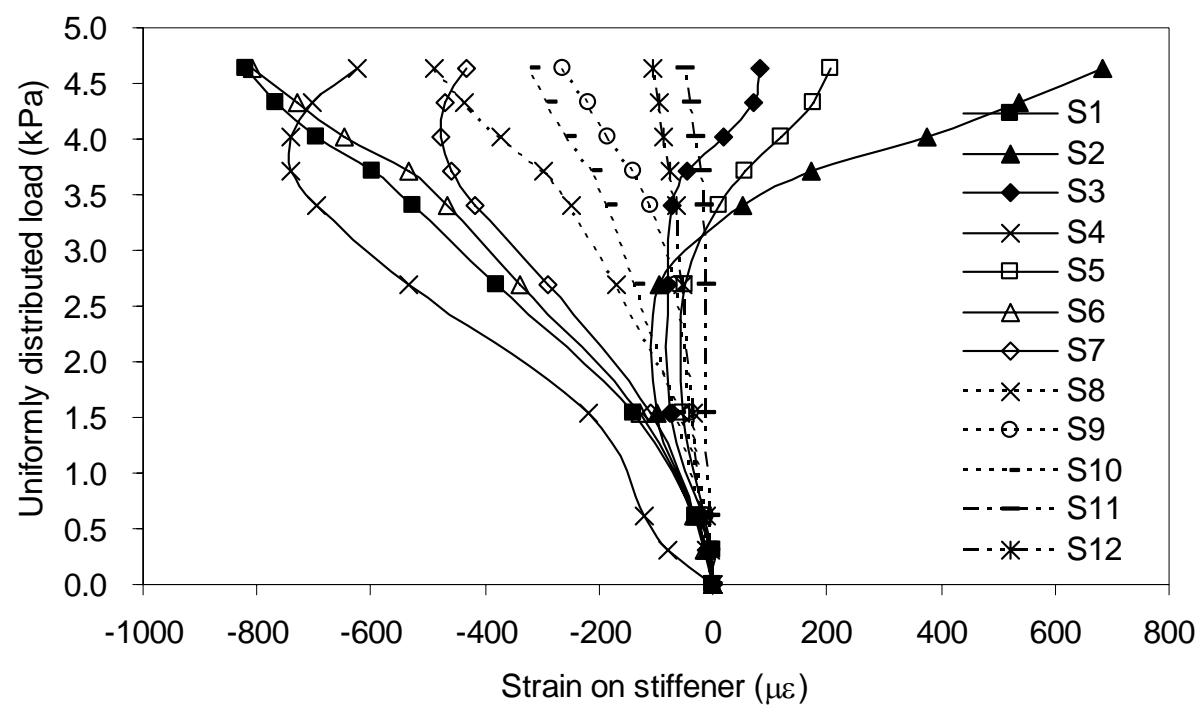

Figure 14. Load-strain curves of stiffener I in specimen BP2 
The strain readings recorded on the base plates are shown in Figures 15a and 15b. Most of these strain gauges were located on the bottom surfaces of the base plates. Figure 15a shows readings from strain gages along the vertical axis of symmetry, while Figure 15b shows those along a diagonal. These strain readings suggest that the bottom surfaces of base plates were generally in tension. This can be easily understood, as the specimen was subject to uniformly distributed loading that led to bending tensile strains (as well as membrane tensile strains at significant deflections) on the bottom surfaces of the base plates. The jumps in the strain values during the initial load steps might have been caused by the imperfect initial shapes of the base plates. Local buckling at a load of around $2.7 \mathrm{kPa}$ is reflected in these readings as at this load level, some of the strain readings show a change in the trend of variation.

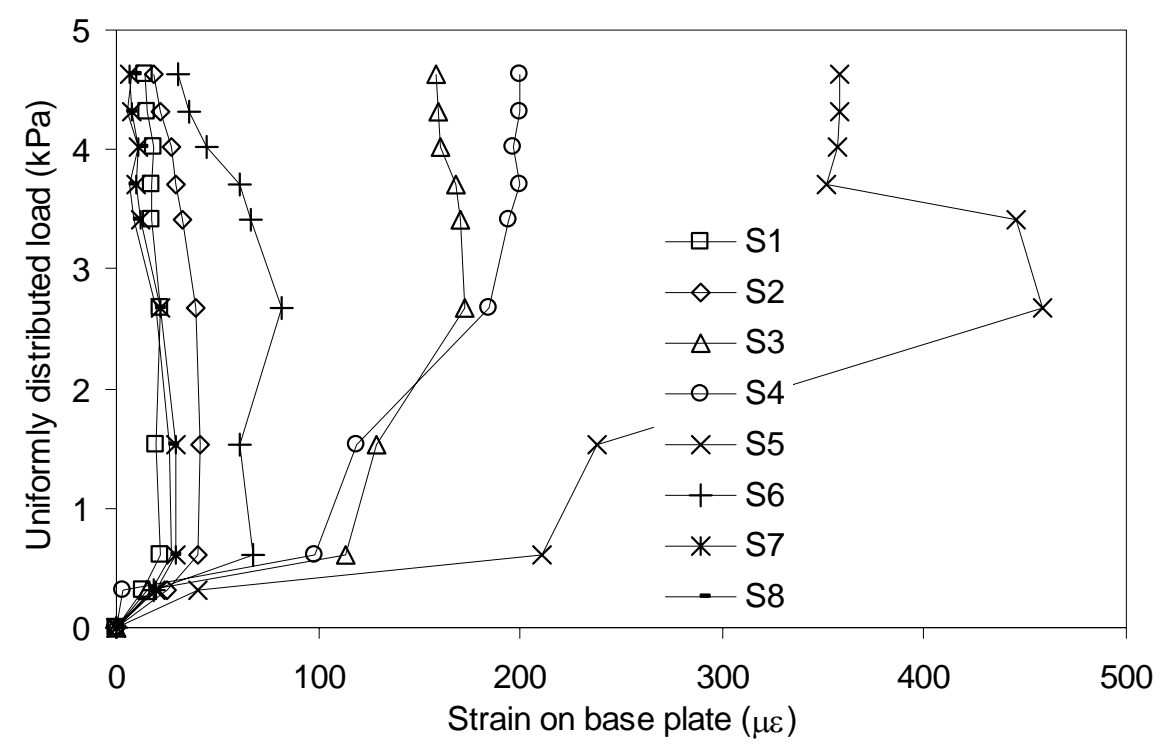

(a) Strain gauges S1-S8

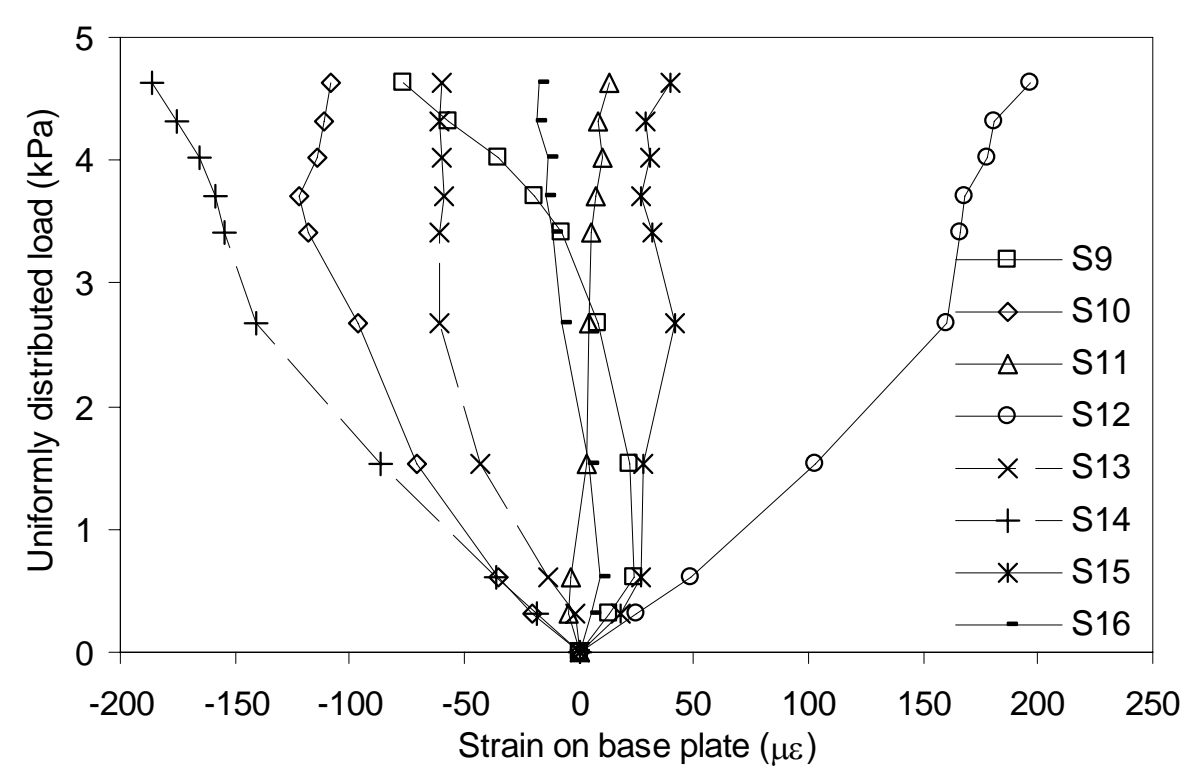

(b) Strain gauges S9-S16

Figure 15. Load-strain curves of base plates in specimen BSP2 
Figure 16 shows the horizontal deformation profile at selected load steps along stiffener II which was selected for displacement monitoring (Figure 10). These readings indicate that before local buckling, the stiffener had almost uniform horizontal displacements along its top edge. Local buckling deformations can be seen at a load of $2.68 \mathrm{kPa}$, which was followed by a stable post-buckling deformation process, during which short-wave buckles continued to grow. These observations are consistent with the strain readings shown in Figure 15.

At the load level of $4.6 \mathrm{kPa}$, plastic deformations in the stiffeners ended the stable post-buckling deformation process, which triggered a large reduction in the overall stiffness of the panel. Final collapse soon followed during the process of adding weights to achieve a load of $4.9 \mathrm{kPa}$. Due to an unexpected problem with the LVDT, the central displacement of panel BP2 was not recorded. As an alternative, the vertical displacement at the intersection of axes B and 2 (Figure 10) is shown against the applied load in Figure 17. An overall view of specimen BP2 after failure is shown in Figure 18a. Figure 18b shows two close-up views of the failure mode, where torsional deformations are seen at the corner joints of modular units.

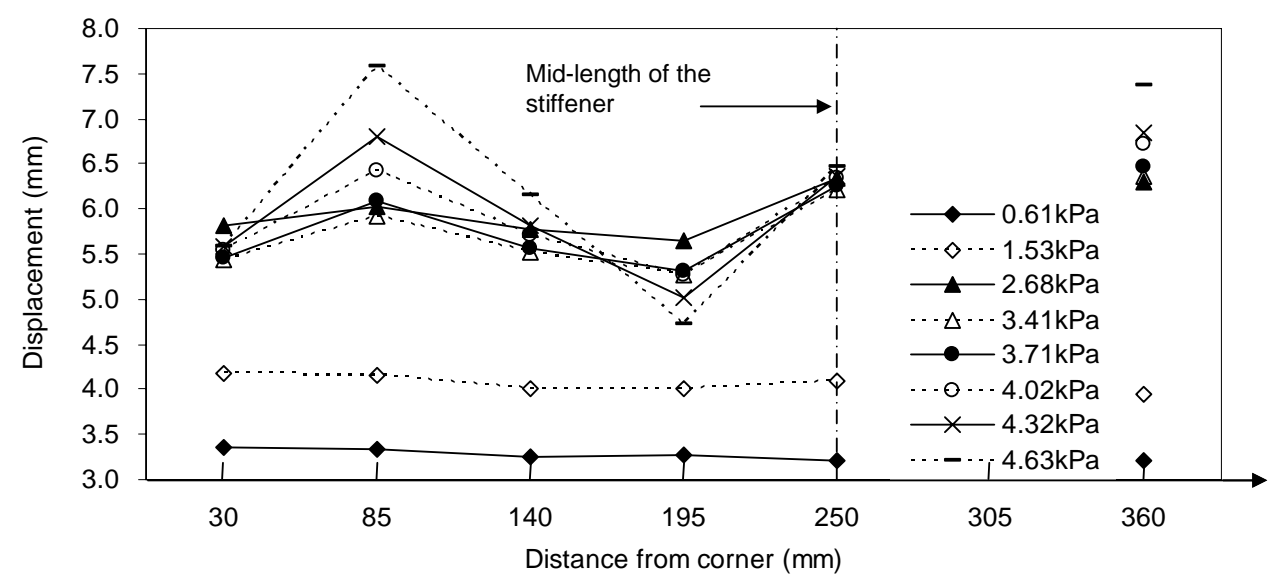

Figure 16. Displacement profiles along stiffener II of specimen BP2

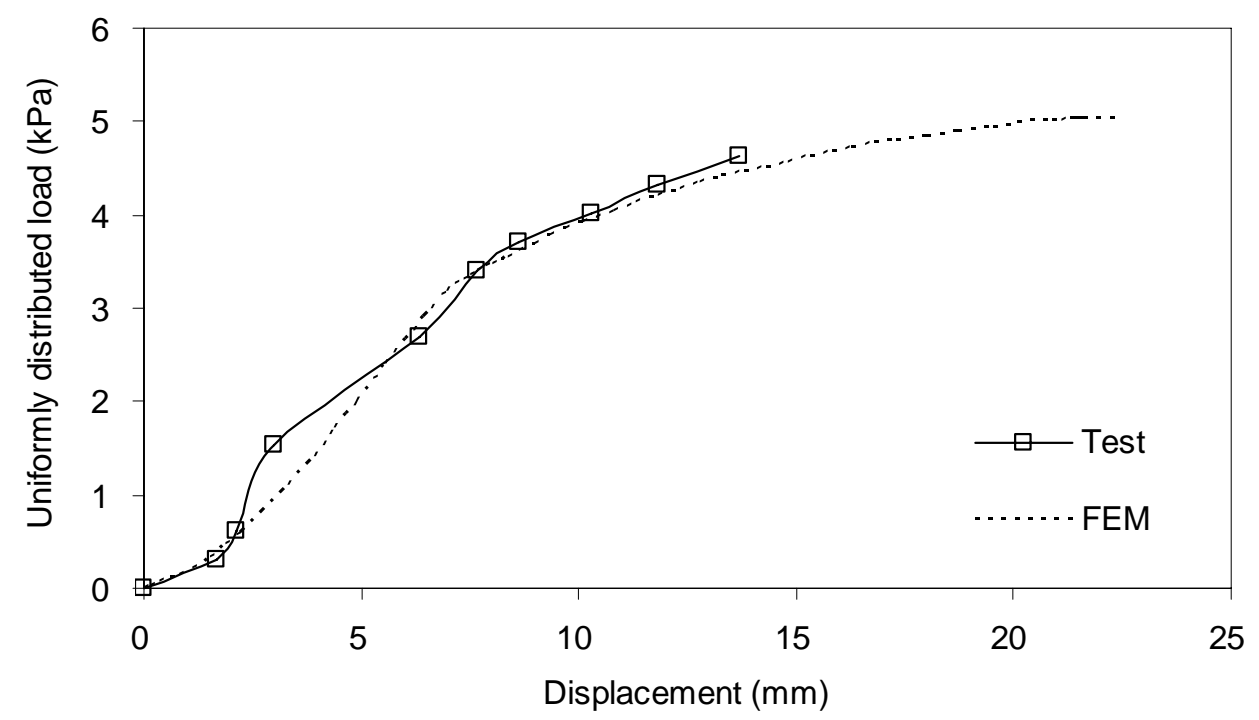

Figure 17. Load-displacement curves of specimen BP2 


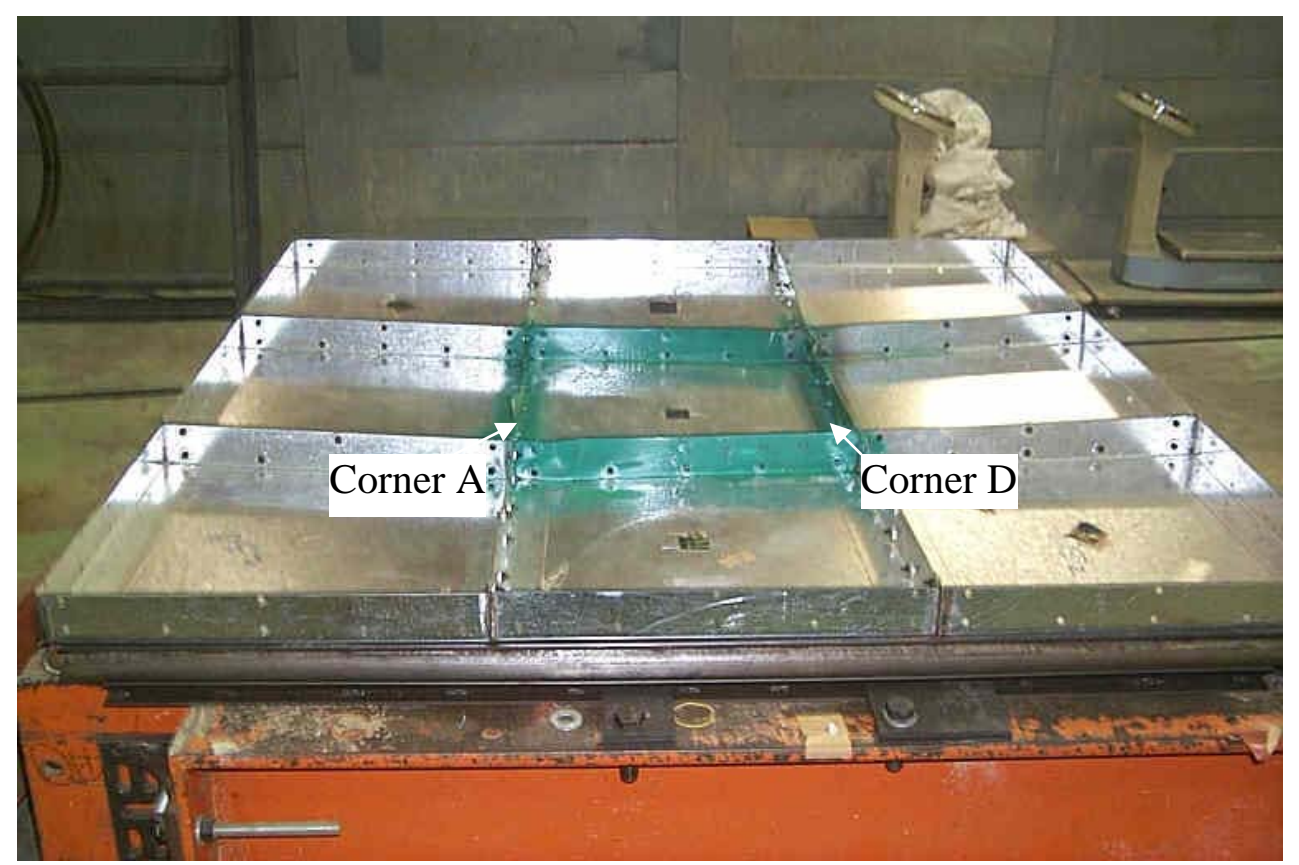

(a) Overall view

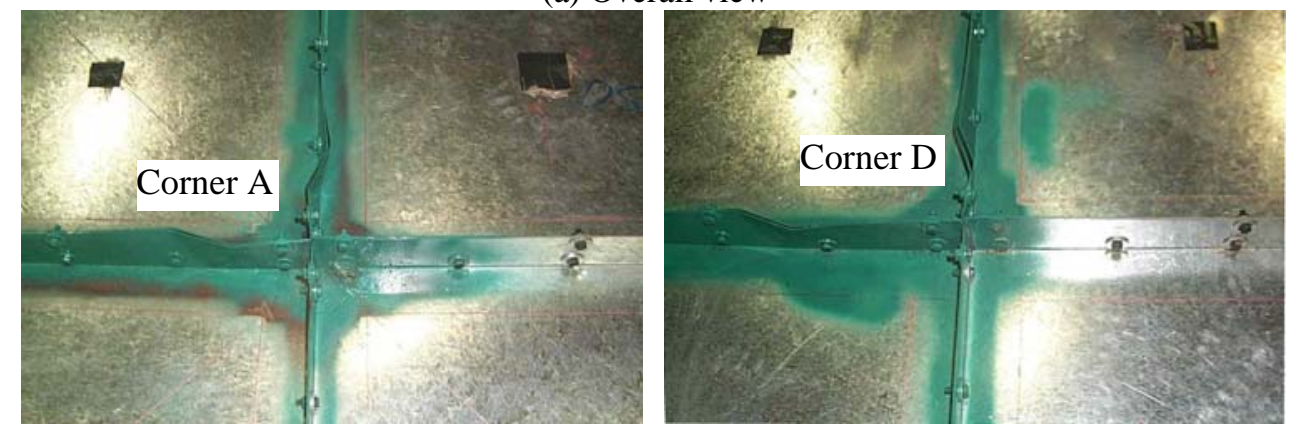

(b) Close-up view

Figure 18. Failure mode of specimen BP2

\subsection{Specimen BP3}

Two tests were conducted on specimen BP3. Strain gauge readings from test BP3-1 are not reported herein, as their readings remained very small during the entire loading process. These readings, however, provided a means for monitoring the structural behaviour and controlling the loading process. Test BP3-1 was stopped at a load of $10.5 \mathrm{kPa}$. The maximum strain recorded in the specimen reached 490, which is well below the yield strain of the steel. The load-deflection curve of the centre of the specimen is shown in Figure 19, which is typical of a plate which stiffens with lateral deflections.

Deformations of the stiffeners were not measured during the BP3-2 test, as the stiffeners were buried in the sand. Figure 20 shows the variations of strains measured on the selected stiffener (Figure 11b). It is clear that these load-strain curves are significantly different from those shown in Figure 14, despite that they were recorded at similar locations. The former are almost linear up to the buckling load, while the latter are more nonlinear and diverge from each other much earlier in the loading process. In test BP3-2, the strains experienced a sudden jump at a load of around $3 \mathrm{kPa}$. 
In particular, several strain gauges recorded abrupt changes from compressive to tensile values (S4, S7, S8 and S10). These changes in strain readings clearly indicate the occurrence of buckling. Moreover, a loud noise was heard at this load level, which was further evidence that buckling had occurred. Subsequently, the specimen entered its post-buckling stage and continued to carry additional loading at the expense of additional deformations. Final collapse happened during the process of adding weights to achieve a load of $4.75 \mathrm{kPa}$.

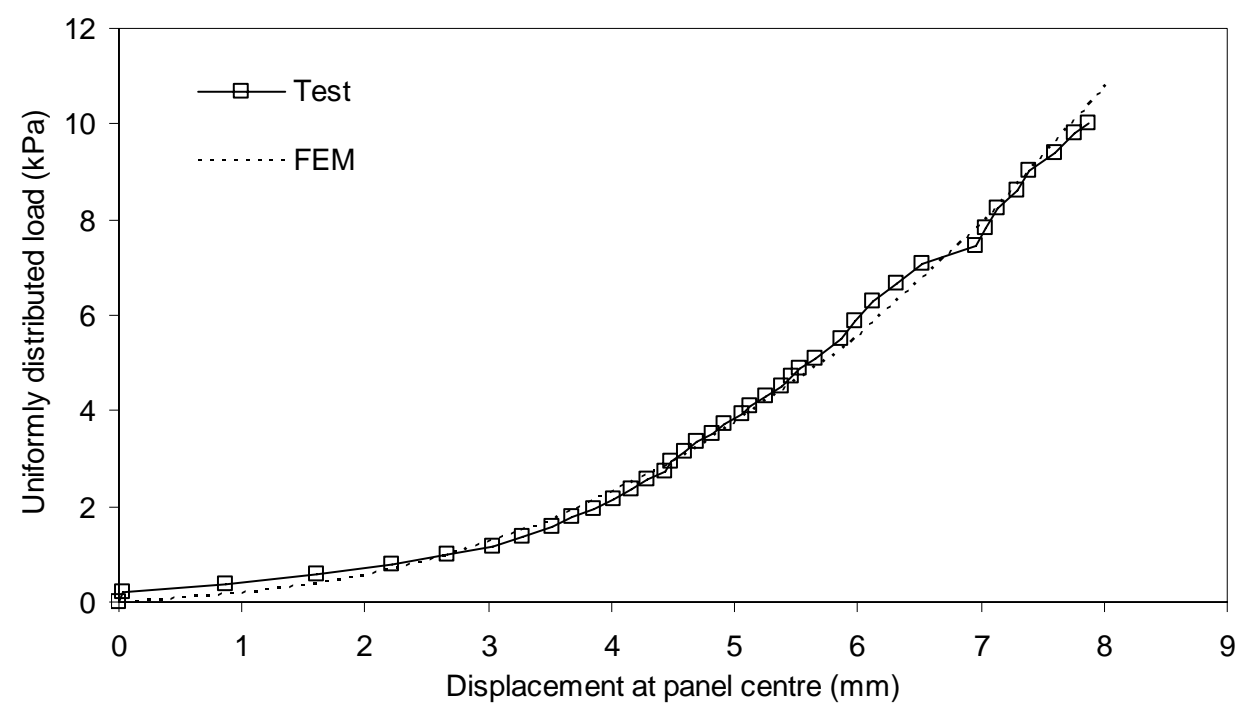

Figure 19. Load-displacement curves of specimen BP3 in test BP3-1

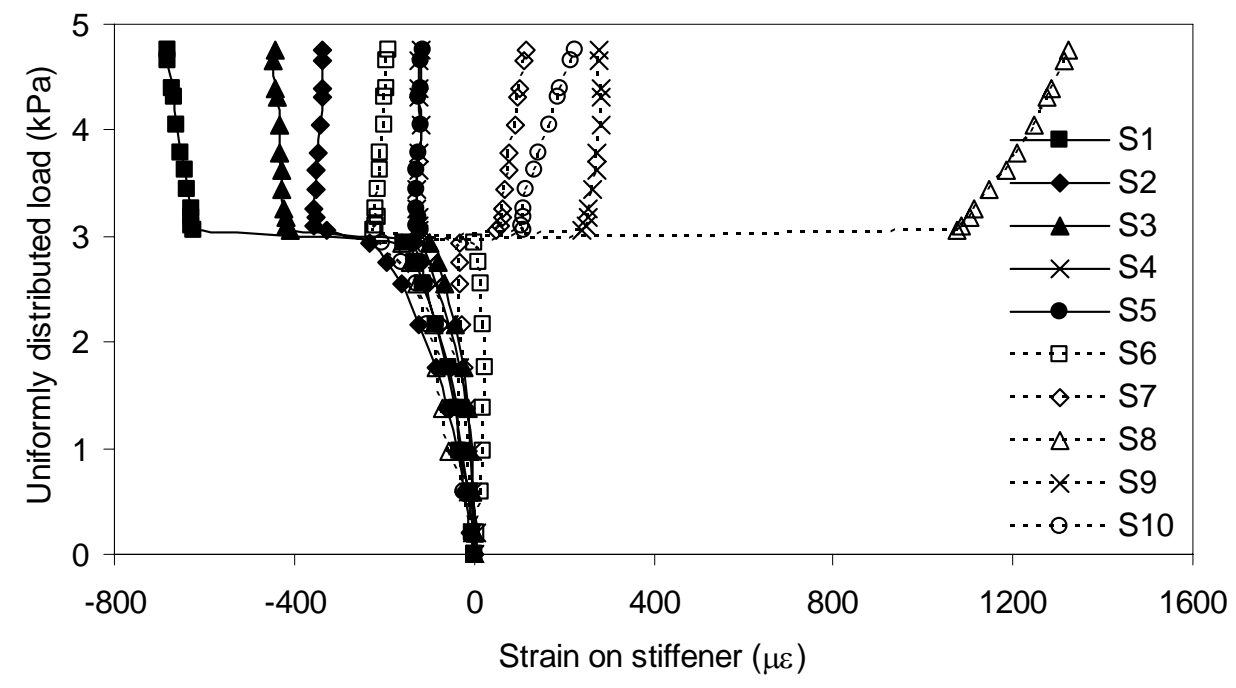

Figure 20. Load-strain curves of selected stiffener in test BP3-2

Figure 21a shows the load-strain responses from strain gauges installed on the base plates (S1-S10). Different from those shown in Figure 15, negative readings were recorded by almost all these strain gauges, as they were attached at the upper surfaces of the base plates. Local buckling of the stiffeners is reflected in these curves by a jump in the strain values at a load level of about $3 \mathrm{kPa}$. The strains on one half of a diagonal of the specimen are shown in Figure 21b (strain gauges S11-S19). It can be seen that except for S16 near a corner, compressive strains developed in the diagonal direction, while tensile strains occurred perpendicular to the diagonal direction. The 
buckling phenomenon of the specimen is also reflected by a sudden jump in these load-strain curves.

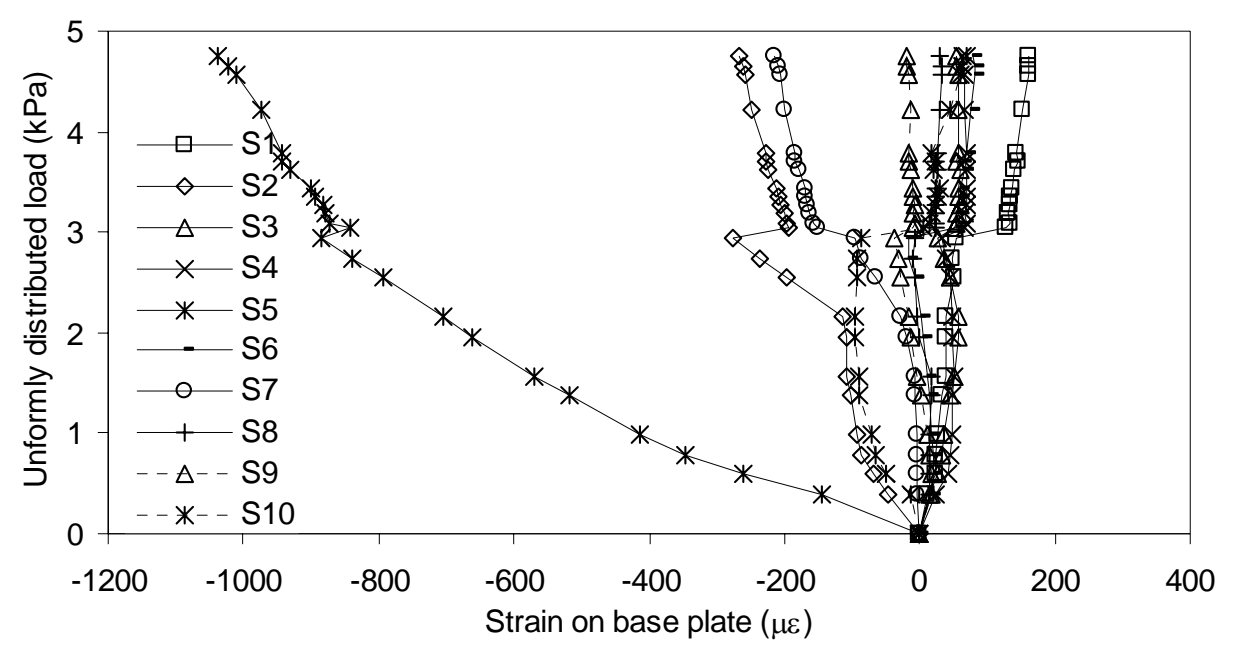

(a) strain gauges S1-S10

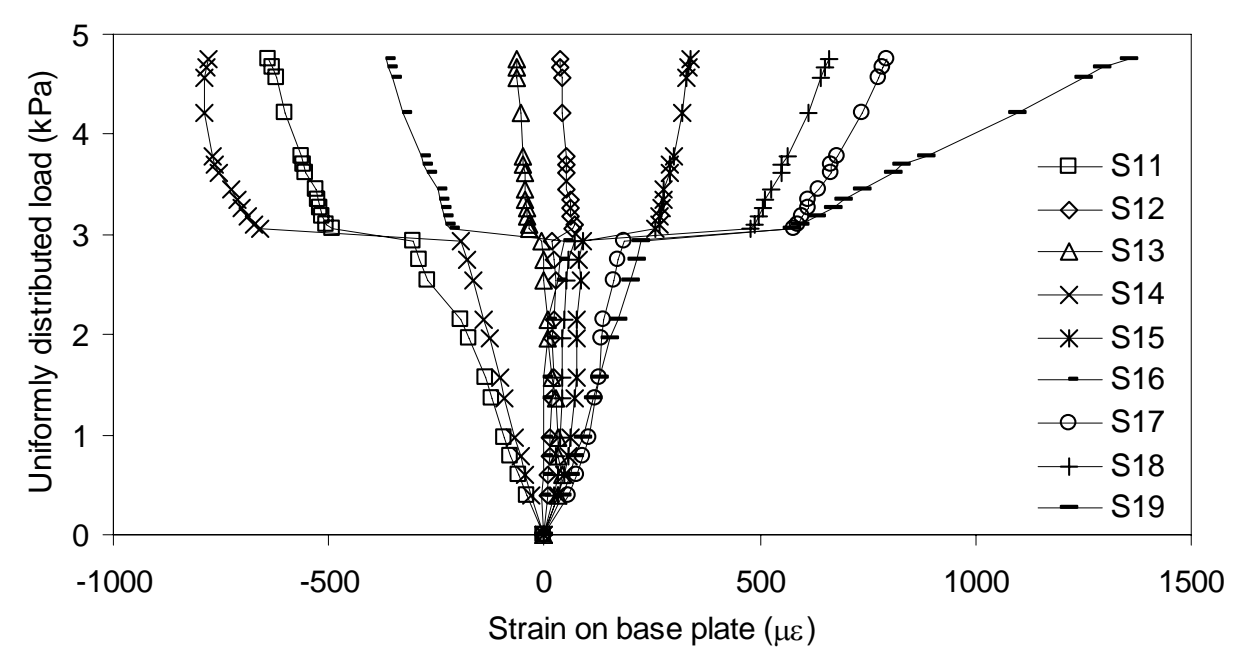

(b) Strain gauges S11-S19

Figure 21. Load-strain curves of base plates in test BP3-2

Figure 22 shows the load-displacement curve of the centre of the specimen, where a sudden increase in the displacement is seen at a load of about $3 \mathrm{kPa}$. This sudden increase in deformation is the result of a snap-though buckling process in a load-controlled test. An overall view of specimen BS3 after the test is shown in Figure 23a. Close-up views of two corner joints are given in Figure 23b, where local buckling of the stiffeners is clearly seen.

The difference in behaviour between test BP2 and test BP3-2 can be attributed to the restraining effect of the sand in test BP3-2. The elastic support of sand reduced the lateral deformations and enhanced the buckling resistance of stiffeners. The stiffeners can be idealized as beams on elastic foundations, which have buckling characteristics similar to those of axially compressed cylindrical shells. This means that when buckling of these elastically restrained stiffeners occurs, the stress level the stiffener can carry has to reduce, leading to the snap-through buckling process. During the 
removal of sand from the panel following the test, it was found that the sand, particularly the bottom layer of the sand, was highly compacted and was difficult to remove.

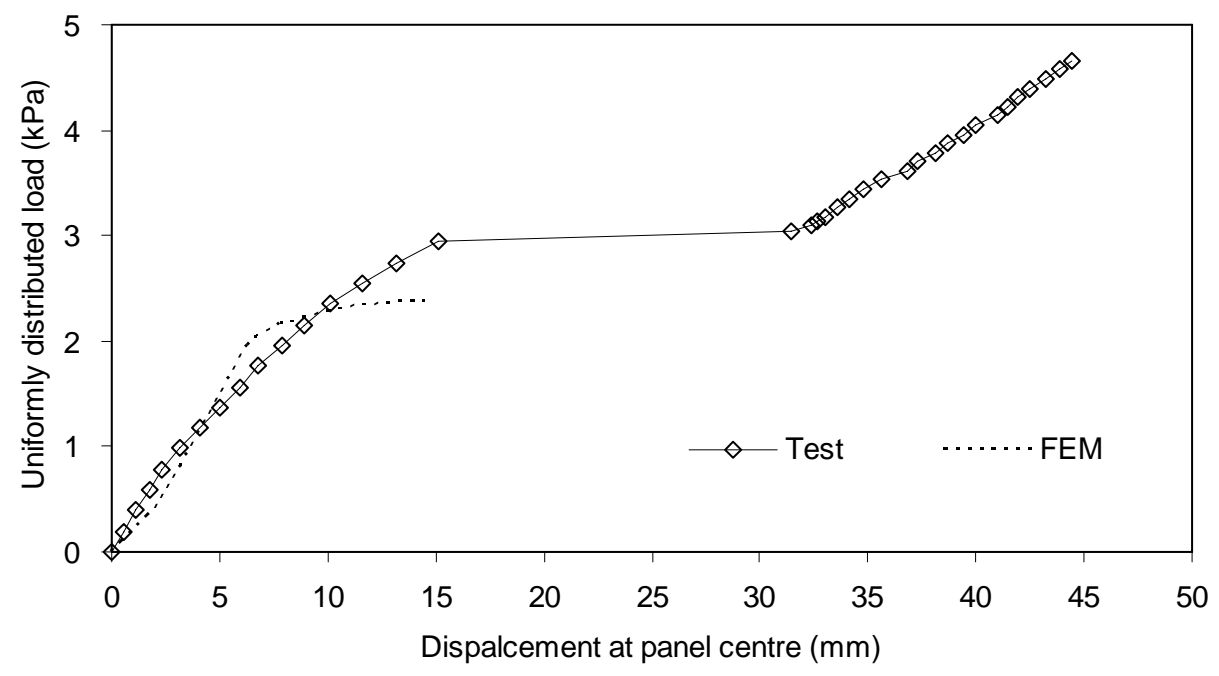

Figure 22. Load-displacement curves at panel centre in test BP3-2

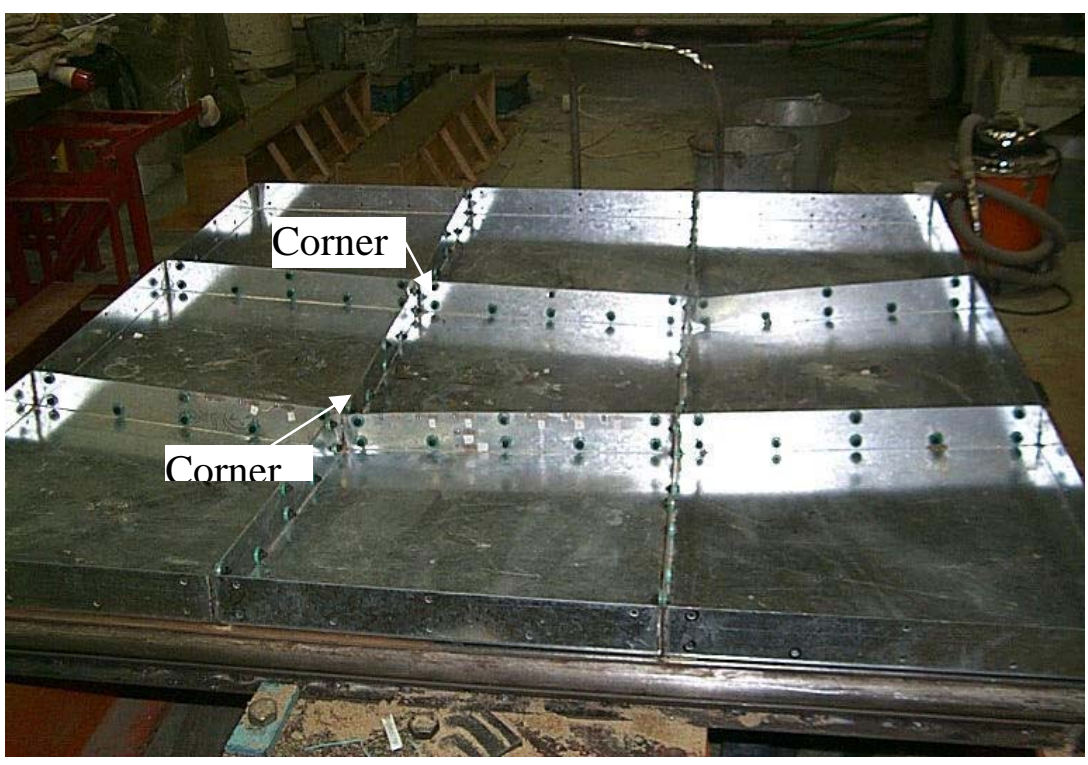

(a) Overall view
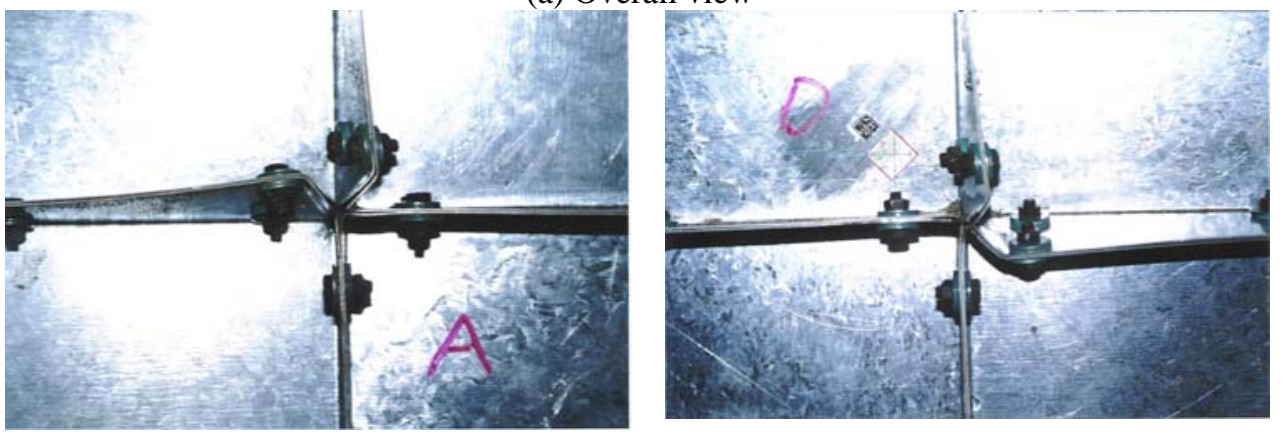

(b) Close-up view

Figure 23. Failure mode of specimen BP3-2 


\section{FINITE ELEMENT MODELLING}

\subsection{General}

The general-purpose finite element package ABAQUS [7] was employed to model the panel tests described above. The boundary condition and method of loading adopted in the finite element analysis followed closely those used in the tests.

Material nonlinearity was included in the finite element model by specifying a stress-strain curve in terms of the true values of stress and strain. The engineering stresses and strains obtained from the tensile tests were converted to true stresses and strains for this purpose. The idealized stress-strain curves adopted in the finite element analysis are multi-linear and were averaged from the tensile tests; they are indicated in Figure 4 using circles and crosses respectively. The primary objective of the finite element study was to arrive at a simple yet accurate connection model which can be used in modelling the buckling behaviour of bolted steel base shells of Comshell roofs. For comparison, a refined finite element model of specimen BP1 with explicitly defined bolts and washers was first investigated and then a simplified approach was explored. Numerical simulations of tests BP2, BP3-1 and BP3-2 were then carried out using the simplified model only. The load-displacement response was traced using the arc-length method (i.e. 'Riks' method). It should be noted that the radius of the round corner between the edge plate and the base plate was not taken into account in the finite element model, as this is believed to have a small effect. Mesh convergence studies were carried out to arrive at accurate meshes (Wong [8]).

\subsection{Refined Bolted Connection Model}

The refined finite element model for specimen BP1 is shown in Figure 24. In this model, the modular unit, bolts and washers were all modelled with deformable elements. These bearing tubes with a diameter of $50 \mathrm{~mm}$ were taken as rigid bodies and prevented from any movements. The panel and the tubes were defined to interact following the hard contact condition with no friction, but rigid body motions of the panel were prevented by appropriate restraints. The hexagon bolt head was modelled as a circular bolt head that circumscribes the original hexagon and this circular bolt head had a diameter of $10 \mathrm{~mm}$. The bolt shank had a nominal diameter of $6 \mathrm{~mm}$ including the threads. In the finite element model, the details of the threads on the shank were neglected but an effective diameter of $5 \mathrm{~mm}$ was used. As the washer generally remained in close contact with the bolt head during the entire loading process, the washer with a diameter of $18 \mathrm{~mm}$ and the bolt head together was treated as an integral component, which simplified the model. The bolt head, washer and shank were all modelled using eight-node hybrid linear solid elements (C3D8H). The performance of this element in modelling bolted connections has been validated by other researchers (Bursi et al. [9]; Wheeler et al. [10]). In particular, this element does not suffer from possible problems of volume strain locking, which can occur with the C3D8 linear element (Bursi et al. [9]. The modular unit was constructed using linear four-node thin shell elements (S4R), with a thickness of $1.03 \mathrm{~mm}$ determined by laboratory measurements made on the steel sheets used in the tests. 


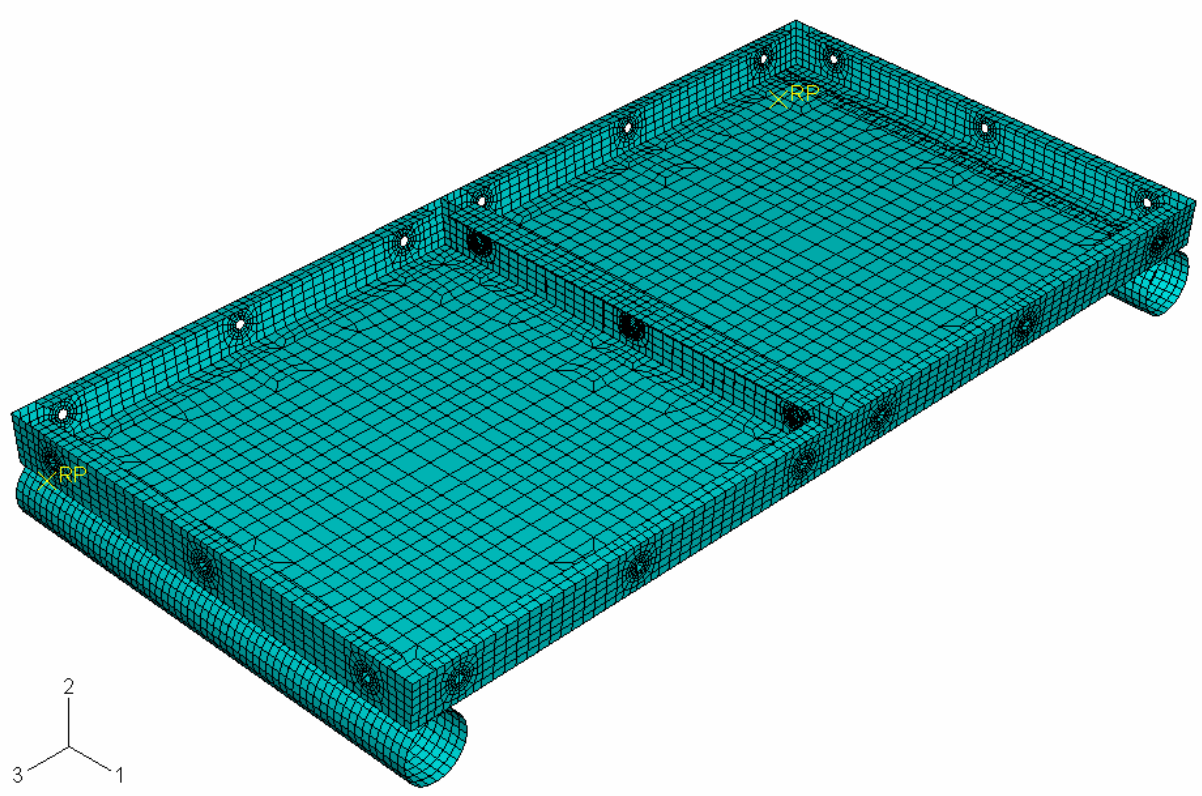

Figure 24. Finite element model for specimen BP1

Contact between adjacent parts was explicitly modelled, including the contact conditions between the washer and the edge plate and between the edge plate pair respectively. Depending on the type of contact problem, two approaches were available in ABAQUS [7] for modelling contact conditions with finite sliding between adjacent parts: (a) defining the contact condition by identifying and pairing potential contact surfaces, and (b) using contact elements. A careful study of the capability of the ABAQUS [7] program revealed that ABAQUS [7] did not include a contact element appropriate for the present purpose, so the surface-based contact modelling technique was adopted. To activate the defined contact condition, the potential contact surfaces were paired up using the "CONTACT PAIR" option provided by ABAQUS [7]. As the shell elements modelling the modular units were surface elements while the bolts and shanks were modelled using solid elements, the possible contact and bearing interaction between the bolt shank and the bolt hole was ignored, which is believed to be acceptable as the diameter of the bolt hole $(6.5 \mathrm{~mm})$ was slightly larger than the diameter of the shank $(5 \mathrm{~mm})$. Moreover, the small-sliding formulation was employed to reduce the computational cost. In this formulation, the corresponding contact surfaces are assumed to undergo only comparatively small relative sliding but arbitrary rotations. A numerical comparison showed that the difference between the general finite-sliding formulation and the small-sliding formulation is negligible for the present problem, but the former is computationally much more efficient.

A "hard" contact condition was defined to model the interaction normal to the two contact surfaces. With this definition, pressures can be transmitted between the two surfaces when they are in contact but disappear when they separate. Two different approaches were employed when considering the interaction tangential to the surfaces. A classical Coulomb friction model, with an assumed coefficient of 0.3 was used in modelling the bolt-to-edge plate interaction. A value of 0.3 or a similar value for the frictional coefficient is commonly used for modelling contact between normal smooth steel surfaces (e.g. Al-Emrani and Kliger [11]). The tangential contact condition between the edge plates was assumed to be perfectly smooth with no inter-surface friction. 
To circumvent the numerical problem of 'overclosure' of the two edge plates, a small gap of $0.1 \mathrm{~mm}$ was introduced between the contact pair of edge plates, through the "ADJUST" and "CLEARANCE" options in ABAQUS [7]. The selected gap magnitude was the result of a large number of trial-and-error calculations aimed at an optimum balance between accuracy and ease for convergence.

The pretension forces in the bolts and the surface-to-surface friction are important parameters in a bolted connection model. The pretension forces in the bolts lead to normal pressures which determine the magnitude of the surface-to-surface frictional force. In the experiments, the bolts were tightened with a spanner by hand. Each bolt was assumed to be subject to a pretension force of $2 \mathrm{kN}$ (around $100 \mathrm{MPa}$ tensile stress in the bolt shank with an effective diameter of $5 \mathrm{~mm}$ ). A parametric study on the effect of the pretension force on the connection behaviour in a simple cantilever connection test (Wong [7]) showed that within the range of $1 \mathrm{kN}$ to $5 \mathrm{kN}$, the actual value of the assumed pretension force has little effect on the predicted response of the connection. To model the complete behaviour of the connection, the analysis was carried out in two stages. In the first stage, the pretension force in the bolt was applied through the "BOLT LOAD" option in ABAQUS [7]. In the second stage, two concentrated loads were applied to the two mid-span corners of the modular unit as was done in the tests. To avoid the rigid body motions of the bolts, additional vertical restraints were applied at the centres of the bolts during the first stage of analysis. These restraints were removed at the beginning of the second stage as the bolts were adequately constrained after the pretensioning.

\subsection{Simplified Bolted Connection Model}

In the simplified bolted connection model, a node within a specified circular area (i.e. tied area) of one edge plate surrounding the bolt hole is assumed to have the same displacements as those of a corresponding node of the other edge plate of the contact pair. That is, these nodes were paired up and constrained using the "TIE" option provided by ABAQUS [7]. Details of the connection such as the bolts and the washers are therefore ignored in this simplified model. In the finite element implementation, three circular layers of elements around each bolt hole were defined. The outer diameter of these three circular layers coincided with diameter of the washer, while that of the innermost layer coincided with the diameter of the bolt head (Figure 25). Two different tied areas were explored for specimen BP1: a diameter of $14 \mathrm{~mm}$ covering two circular layers of elements and a diameter of $10 \mathrm{~mm}$ cover the innermost layer of elements. For specimens BP2 and BP3, only the latter option was used. With such an arrangement, both the translational and rotational degrees of freedom of the tied nodes have the same displacement values during the deformation process. Over the remaining parts, the pair of edge plates was coupled using the surface-based contact definition (ABAQUS [7]) (Figure 25).

The finite element model for specimens BP2 and BP3 is shown in Figure 26. By eliminating the details of the bolts and the washers from the finite element model, only around 10,600 and 110,000 elements were required to model specimens BP1 and BP2 or BP3 respectively in the simplified approach. As a result, a single numerical simulation of specimen BP1 using the simplified model only took about 50 minutes instead of around 180 minutes required by an analysis using the refined model on the same computer, which represents a dramatic reduction in the computational cost as a result of the simplifications. 


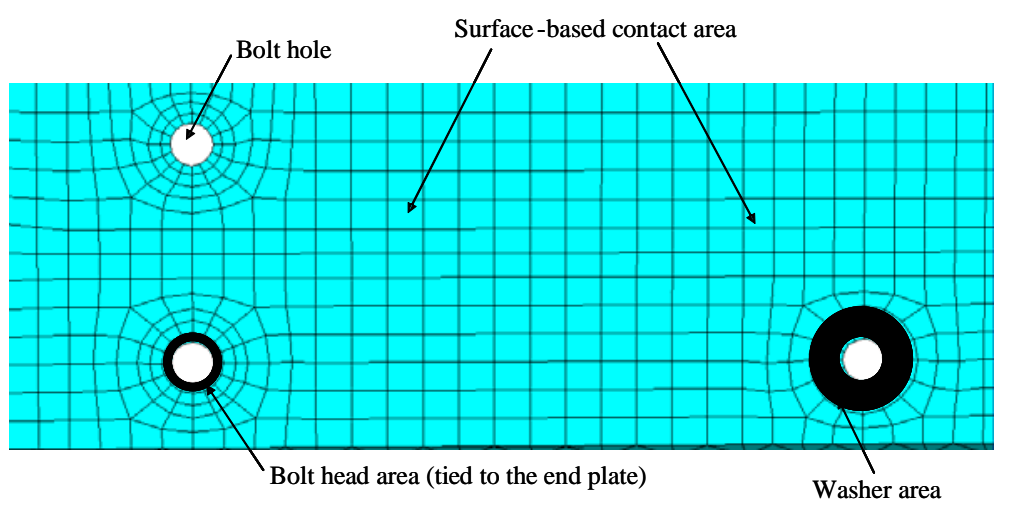

Figure 25. Contact definitions in the simplified model

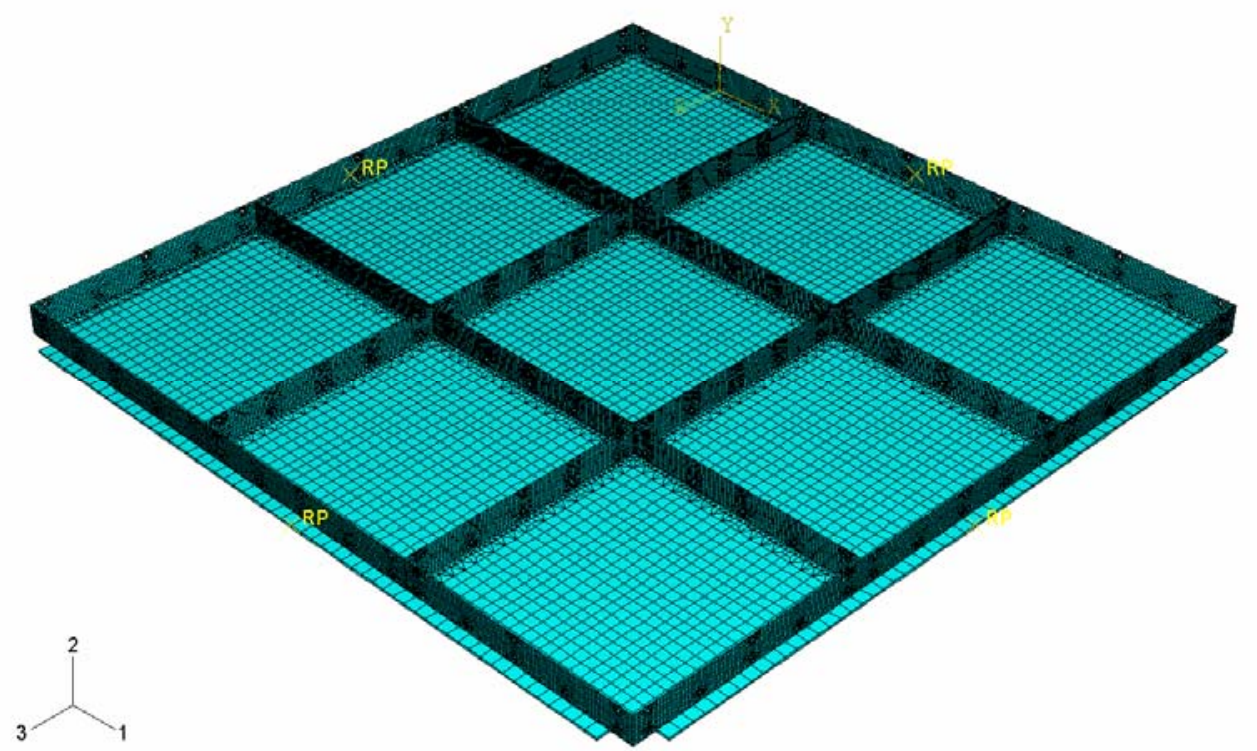

Figure 26. Finite element model for specimens BP2 and BP3

\section{COMPARISON BETWEEN TEST AND FINITE ELEMENT RESULTS}

\subsection{Refined Bolted Connection Model}

The finite element load-displacement curve for the centre of the BP1 specimen is compared with the test curve in Figure 13. In general, the numerical results are in close agreement with the test results. However, the finite element model tends to overestimate the structural resistance in the final stage of deformation. This softer behaviour of the test specimen can be attributed to the slight relative twisting between the two modular units at the connection observed in the test. These non-symmetric deformations were due to the small geometric distortions in the test specimen which were not included in the finite element model.

The deformed shape superimposed with the contours of the von Mises equivalent stress at the maximum load predicted by the refined finite element model is shown in Figure 27. It is clear that 
the finite element deformed shape agrees well with that from the experiment.

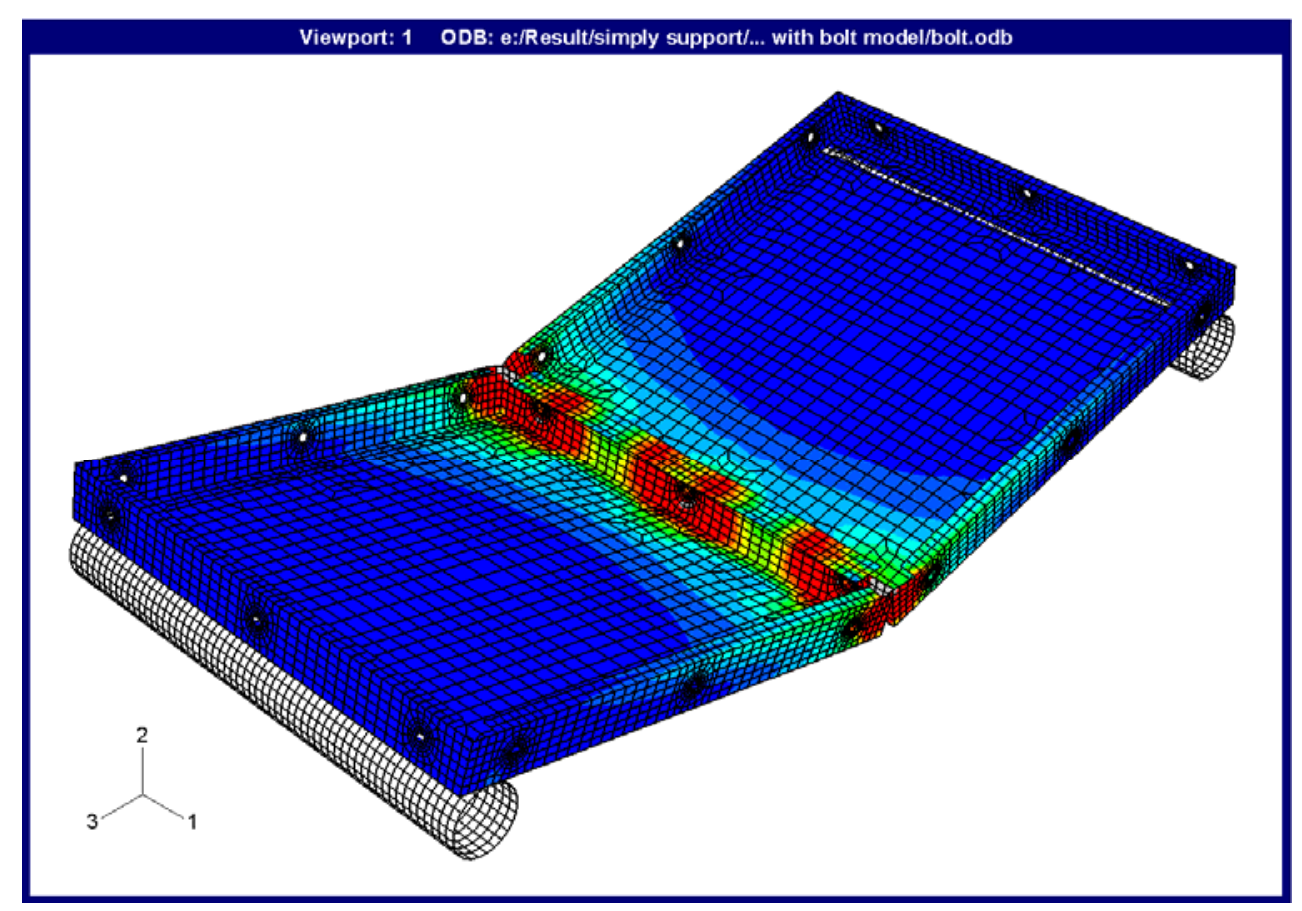

Figure 27. Deformed shape and stress distribution from finite element analysis for test BP1

\subsection{Simplified Bolted Connection Model}

\subsubsection{Test BP1}

The results of the two finite element simulations using the simplified model are also shown in Figure 13. It is seen that the load-displacement curves from the numerical analyses with two different tied areas agree well with the experimental curves in the initial stage. At higher loads, the finite element curves deviate from the test curve. In the modelling of specimens BP2 and BP3, only the more conservative option of a tied area of $10 \mathrm{~mm}$ in diameter was adopted.

Again, the numerical models overestimate the structural resistance significantly in the final stage of deformation. The deformed shapes superimposed with the contour plots of the von Mises equivalent stress from the simplified finite element models at the maximum load are similar to that predicted by the refined model and are not shown here.

\subsubsection{Test BP3-1}

The load-displacement response at the centre of the panel predicted by ABAQUS [7] is shown in Figure 19, which is seen to be in prefect agreement with the experimental results. Figure 28 presents the predicted failure mode and the corresponding stress distribution at the ultimate load (42.6 kPa), while the experiment stopped at the load of $7.8 \mathrm{kPa}$.

\subsubsection{Tests BP2 and BP3-2}

The load-displacement curve for the point of intersection between axes B and 2 (Figure 10b) from test BP2 is given in Figure 17. The numerical simulation was stopped due to the divergence of the 
iterative solution process. Figure 17 shows that the load-displacement curve predicted by ABAQUS [7] is in good agreement with that from the test.

For test BP3-2, Figure 22 shows that the load-displacement response predicted by ABAQUS [7] is significantly different from the experimental curve. In fact, they are significantly different right from the beginning of loading. Both the buckling load and the deep post-buckling path obtained form the test could not be predicted by the numerical model. Since the effect of the sand during the test was omitted in the numerical model, the fact that finite element buckling load is lower than the experimental value may be interpreted to imply that the sand enhanced the buckling strength of the panel. The discrepancies observed between the numerical and the experimental behaviour can thus be attributed to the presence of the sand during the test. Figures 29 and 30 show the deformed shapes and the corresponding distributions of the von Mises equivalent stress at the maximum load for tests BP2 and BP3-2, respectively.

As the load increased, material yielding firstly occurred within the bolted area. However, the panel continued to deform with its global behaviour little affected by such local stress concentration and yielding. The magnitude of stresses continued to grow with further loading, leading to obvious concentration of yielding in certain regions on the stiffeners. It should be noted that the stress distribution is much more uniform on specimen BP2 than specimen BP3-2. High stresses are mainly observed at the four corners of the central unit, which agrees well with the test observation (Figures 18b and 23b). Despite this discrepancy, the deformed shapes of specimen BP2 and BP3-2 predicted by ABAQUS [7] are similar. The stresses in the base plates from the finite element analyses remain small during the loading process, which are consistent with the measurements from the test. These comparisons show that the ultimate failure of the specimens occurred as a result of the buckling of stiffeners. In addition, the finite element models are able to accurately capture the buckling behaviour observed in the tests (Figures 18 and 23).

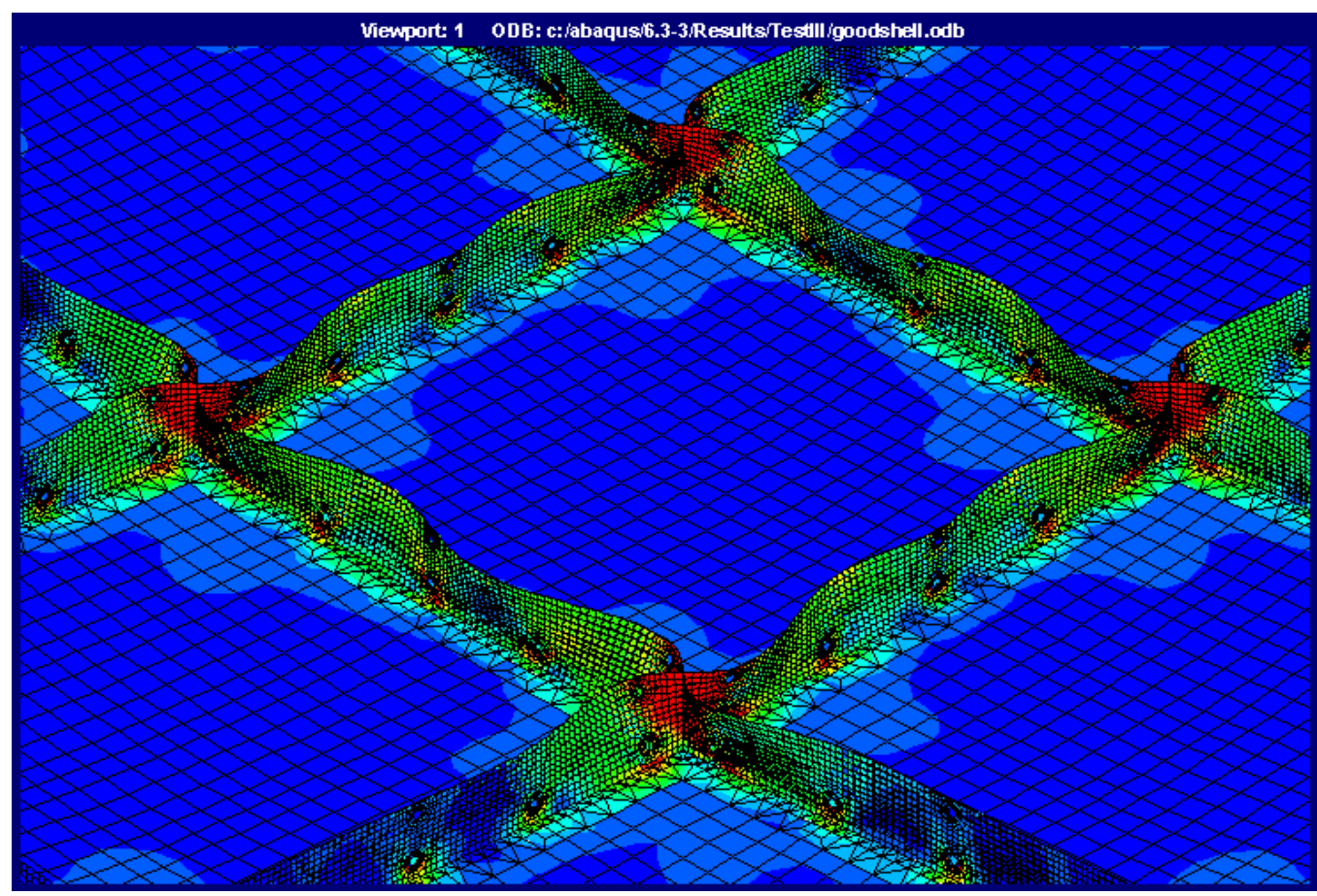

Figure 28. Deformed shape and stress distribution from finite element analysis for test BP3-1 


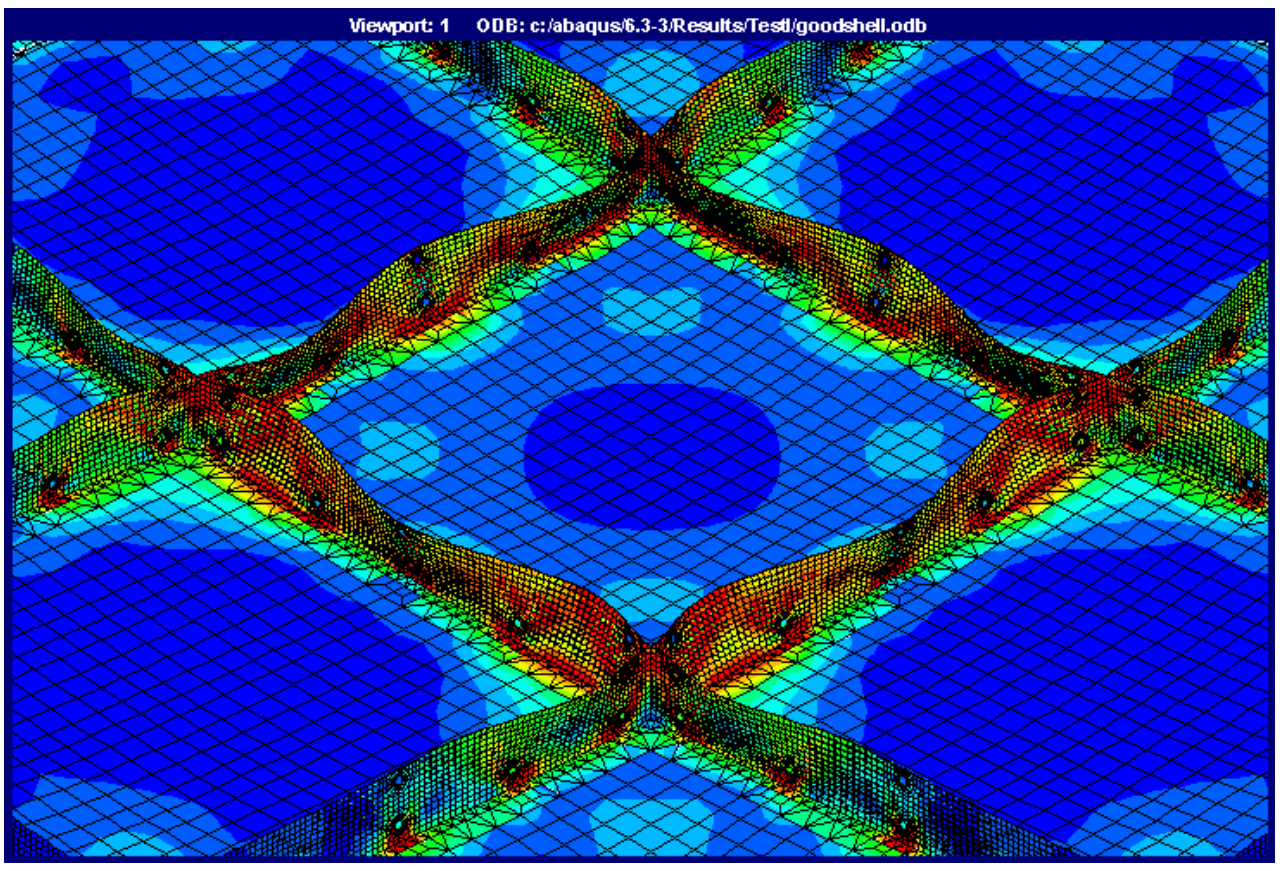

Figure 29. Deformed shape and stress distribution from finite element analysis for test BP2

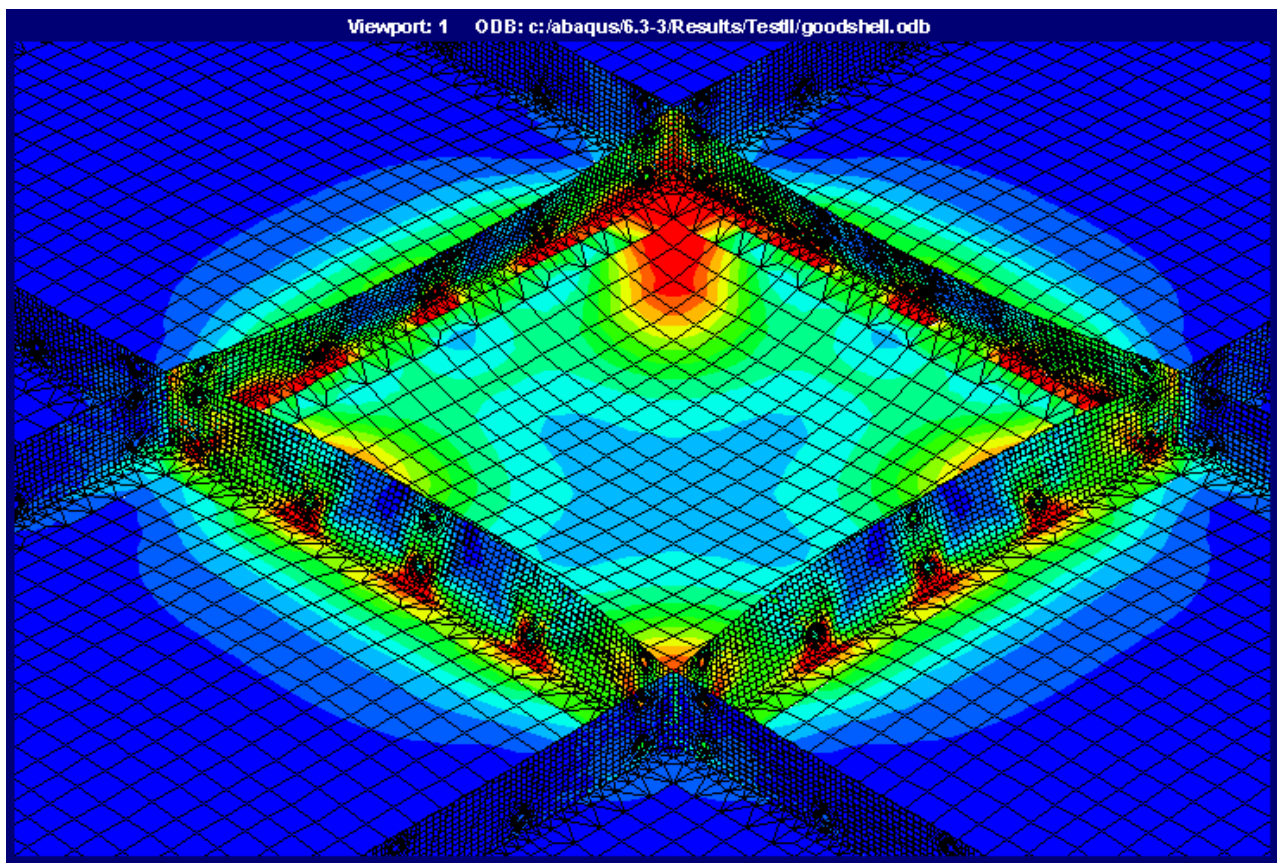

Figure 30. Deformed shape and stress distribution from finite element analysis for test BP3-2

\section{CONCLUSIONS}

A Comshell roof consists of a bolted steel base shell and cast in-situ concrete in composite action. A key design issue of Comshell roofs is the buckling strength of the steel base shell under wet concrete loading during construction. The behaviour of these bolted shells is complicated by the presence of many bolted joints, so the use of finite element analysis is necessary in order to accurately predict their behaviour. This paper has been concerned with the flexural behaviour of these bolted joints through a series of tests conducted on bolted flat panels featuring such joints and the numerical modelling of this behaviour. 
The tests showed that the main failure mode of bolted panels under transverse loading is the buckling of the stiffeners as the upper part of the stiffeners is subject to longitudinal compression. It was also found that this buckling behaviour was affected by the presence of filled sand used to apply loading. The sand enhanced the buckling load of the panel but also led to sudden a snap-through buckling failure.

Finite element analyses incorporating a simplified connection model were developed for modelling the behaviour of the test panels. The finite element results were first compared with those from a simple two-unit panel test, and then compared with those from nine-unit panel tests. These comparisons showed that the simplified connection model, in which the bolt connections were simulated using the "TIE" option of the ABAQUS [7] program, led to accurate results with the choice of an appropriate tied area and without the presence of filled sand. Based on these comparisons, it can be concluded that the simplified connection model has the potential to be used in modelling bolted base shells of real shell roofs.

\section{ACKNOWLEDGEMENTS}

This work has been supported by the Research Grants Council of the Hong Kong Special Administrative Region, China (Project No: PolyU 5059/99E), with additional support from The Hong Kong Polytechnic University. The authors are grateful for this support.

\section{REFERENCES}

[1] Medwadowski SJ. Concrete thin shell roofs at the turn of the millennium. Current and Emerging Technologies of Shell and Spatial Structures. Proceedings of an IASS Symposium, April, 1998:9-22.

[2] Teng JG. Steel-concrete composite shells for enclosing large spaces. Proceedings, International Conference on Steel and Composite Structures, Pusan, Korea, 14-16 June, 2001:403-409.

[3] Teng, JG, Wong HT, Wang ZC, Dong SL. Steel-concrete composite shell roofs: structural concept and feasibility. Advances in Structural Engineering 2005:8(3), in press.

[4] Wong HT, Teng, JG. Buckling behaviour of model steel base shells of the Comshell roof system. Journal of Constructional Steel Research; 2005, in press.

[5] BSEN1002. Metallic Materials-Tensile Testing-Part 1: Method of Test at Ambient Temperature. European Committee for Standardization, Brussels; 2001.

[6] Timoshenko SP, Woinowsky-Krieger S. Theory of Plates and Shells, 2nd Edition. McGraw-Hill Book Company, 1959.

[7] ABAQUS. ABAQUS standard user’s manual, version 6.3; 2003. 
[8] Wong HT. Behaviour and Modelling of Steel-Concrete Composite Shell Roofs. PhD Thesis, The Hong Kong Polytechnic University; 2005.

[9] Bursi OS, Jaspart JP. Calibration of a finite element model for bolted end plate steel connections. Journal of Constructional Steel Research 1997;44:225-262.

[10] Wheeler AT, Clarke MJ, Hancock GJ, FE Modeling of four-bolt, tubular moment end-plate connections. Journal of Structural Engineering, ASCE 2000;122:1307-1316.

[11] Al-Emrani M, Kliger R. FE analysis of stringer-to-floor-beam connections in riveted railway bridges. Journal of Constructional Steel Research 2003;59:803-818. 